\title{
No Guarantees, No Trade: How Banks Affect Export Patterns
}

Niepmann, Friederike and Tim Schmidt-Eisenlohr

Niepmann, Friederike and Tim Schmidt-Eisenlohr (2016). No

Guarantees, No Trade: How Banks Affect Export Patterns.

International Finance Discussion Papers 1158.

http://dx.doi.org/10.17016/IFDP.2016.1158

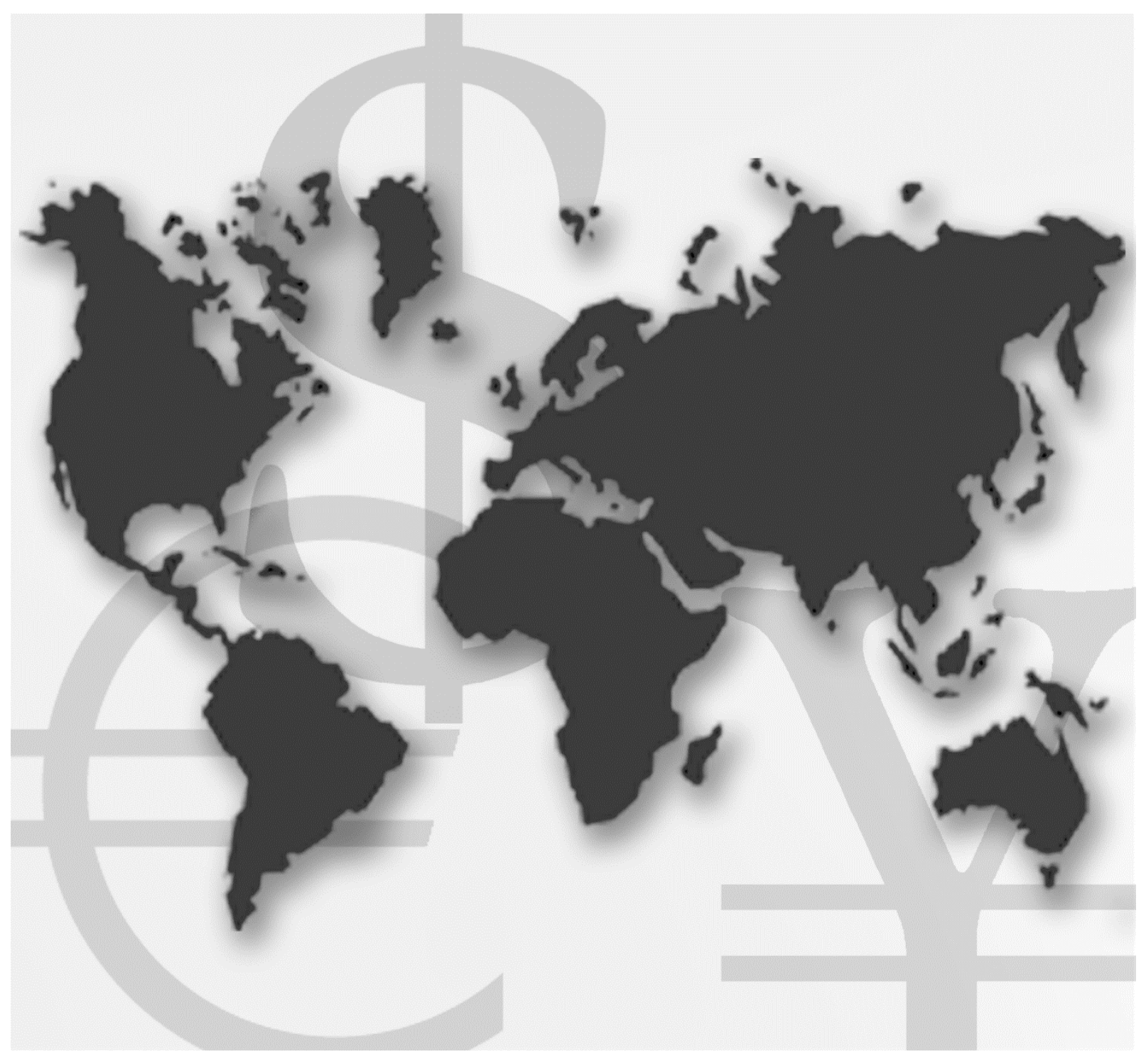

\section{International Finance Discussion Papers}

Board of Governors of the Federal Reserve System

Number 1158

January 2016 


\section{Board of Governors of the Federal Reserve System \\ International Finance Discussion Papers}

Number 1158

January 2016

\section{No Guarantees, No Trade: How Banks Affect Export Patterns}

Friederike Niepmann

Tim Schmidt-Eisenlohr

NOTE: International Finance Discussion Papers are preliminary materials circulated to stimulate discussion and critical comment. References to International Finance Discussion Papers (other than an acknowledgment that the writer has had access to unpublished material) should be cleared with the author or authors. Recent IFDPs are available on the Web at www.federalreserve.gov/pubs/ifdp/. This paper can be downloaded without charge from the Social Science Research Network electronic library at www.ssrn.com. 


\title{
No Guarantees, No Trade: How Banks Affect Export Patterns*
}

\author{
Friederike Niepmann and Tim Schmidt-Eisenlohr ${ }^{\dagger}$
}

\begin{abstract}
How relevant are financial instruments to manage risk in international trade for exporting? Employing a unique dataset of U.S. banks' trade finance claims by country, this paper estimates the effect of shocks to the supply of letters of credit on U.S. exports. We show that a one-standard deviation negative shock to a country's supply of letters of credit reduces U.S. exports to that country by 1.5 percentage points. This effect is stronger for smaller and poorer destinations. It more than doubles during crisis times, suggesting a non-negligible role for finance in explaining the Great Trade Collapse.
\end{abstract}

Keywords: trade finance, global banks, letter of credit, exports, financial shocks JEL-Codes: F21, F23, F34, G21

${ }^{*}$ The authors would especially like to thank Geoffrey Barnes and Tyler Bodine-Smith for excellent research assistance. For their helpful comments, they would also like to thank Mary Amiti, Pol Antras, Andrew Bernard, Gabriel Chodorow-Reich, Stijn Claessens, Giancarlo Corsetti, Pablo D'Erasmo, Martin Goetz, Kalina Manova, Atif Mian, Daniel Paravisini, Steve Redding, Peter Schott, Philipp Schnabl, Mine Z. Senses, David Weinstein, and members of the D.C. trade group as well as participants in seminars at New York Fed, San Francisco Fed, Federal Reserve Board, LMU Munich, Ifo Institute Munich, Bank of England, University of Oxford, University of Passau, University of Cambridge, Graduate Institute, LSE, and the following conferences: NBER SI International Macro \& Finance, SED 2015, AEA 2015, Econometric Society World Congress 2015, FIRS 2014, RMET 2014 and CESifo Conference on Macro, Money and International Finance.

${ }^{\dagger}$ The authors are staff economists in the Division of International Finance, Board of Governors of the Federal Reserve System, Washington, D.C. 20551 U.S.A. The views in this paper are solely the responsibility of the author(s) and should not be interpreted as reflecting the views of the Board of Governors of the Federal Reserve System or of any other person associated with the Federal Reserve System. Corresponding author: Tim Schmidt-Eisenlohr. Email: t.schmidteisenlohr@gmail.com. Address: Federal Reserve Board, Constitution Avenue, Washington, DC. Phone: 202-872-7564. 


\section{Introduction}

Trading across borders exposes firms to substantial risks. Exporters can mitigate these risks by buying trade finance products from banks, most importantly letters of credit. These services represent a substantial business for the financial sector. In 2012, about 8 percent of U.S. exports or $\$ 116$ billion were covered by letters of credit. ${ }^{1}$ World-wide, letters of credit guaranteed more than $\$ 2.3$ trillion or 12.5 percent of international trade in the same year. ${ }^{2}$

The 2008/2009 financial crisis has heightened the interest in this business from policy makers and the private sector. There was a perception of a so-called trade finance gap, that is, a potential undersupply of trade finance during the crisis by the financial sector. In response to this, many international organizations and the G20 committed to increasing their trade finance support. ${ }^{3}$ Special steps were taken in the Basel III capital rules to protect the trade finance business. In the wake of the financial crisis and the European debt crisis, the lower capitalization of banks has led financial institutions to begin refinancing trade finance through securitization.

Despite the size and the large interest in this business, there is little evidence on its relevance for international trade. In particular, it remains an open question whether reductions in the supply of letters of credit harm trade. Firms typically have the option to sell and buy without the involvement of banks by settling the trade on pre-payment (cash-in-advance) or post-payment (open account) terms. So a firm that cannot get a letter of credit might simply switch to one of these alternative payment forms without changing its trade volume. However, letters of credit are special in their ability to reduce risk in international trade and potential substitutes are imperfect. ${ }^{4}$ Antràs and Foley (forthcoming), for example, show that letters of credit are key for the creation of new trade relationships, and Schmidt-Eisenlohr (2013) shows theoretically that switching to alternative payment forms may be very costly.

This paper exploits a unique dataset available at the Federal Reserve to show that reductions in the supply of letters of credit by banks have causal effects on U.S. exports. The

\footnotetext{
${ }^{1}$ A letter of credit guarantees payment to the exporter against a set of documents presented to the bank that prove the delivery of goods to the importer. Payment choices are discussed in more detail below.

${ }^{2}$ These figures are based on information on letter-of-credit messages sent through SWIFT from the SWIFT Institute.

${ }^{3}$ The G20, for example committed to increasing its support of trade finance by $\$ 250$ billion over a two-year period. See G20 (2009).

${ }^{4}$ Trade credit insurance that can be bought in conjunction with open account, for example, is not a good substitute for a letter of credit. While insurance shifts risk from the exporter to the insurer, a letter of credit reduces the real risk in the economy by providing a commitment device for the importer. For very risky countries, trade credit insurance is therefore often very costly or even unavailable.
} 
effects are stronger for smaller and poorer destination countries, where fewer U.S. banks are active, and are twice as big during crisis times than during tranquil times. While earlier studies have focussed on the effects of shocks to the supply of credit, we explore the effects of a reduction in trade-specific financial instruments. ${ }^{5}$ We term this new channel through which financial shocks are transmitted to the real economy and across borders the letter-ofcredit or risk channel. Besides contributing to the literature on finance and trade, we also add to a set of recent papers that have shown real effects of financial shocks for employment (Chodorow-Reich (2014)), firm liquidity (Khwaja and Mian (2008)) and durable consumption (Mian and Sufi (2010)), among others. ${ }^{6}$ In carrying out our analysis, we also present several methodological innovations building on the approach proposed by Greenstone et al. (2014) and Amiti and Weinstein (2013) to structurally estimate supply shocks. ${ }^{7}$

Information on trade finance employed in this paper is from the FFIEC 009 Country Exposure Report that all large U.S. banks are required to file. ${ }^{8}$ We observe banks' trade finance claims, which reflect mostly LCs in support of U.S. exports, by destination country at a quarterly frequency over a period of 15 years. The total trade finance claims of all reporting banks account for roughly 20 percent of U.S. exports in 2012. Thus, the trade finance activities captured in the report are sizable relative to trade.

Based on these data, we estimate time-varying trade finance supply shocks. To isolate idiosyncratic supply shocks from demand shocks, trade finance growth rates at time $t$ in country $c$ are regressed on bank-time fixed effects $\alpha_{b t}$ as well as on country-time fixed effects $\beta_{c t}$. The estimated bank-time fixed effects $\alpha_{b t}$ correspond to idiosyncratic bank-level supply shocks. To address potential endogeneity concerns, we estimate bank-time fixed effects separately for each country, always dropping country $i$ information from the sample to obtain the bank shocks that we use for country $i$. We show that bank shocks are positively correlated with growth in loans and negatively correlated with banks' credit default swap spreads. This is evidence that the estimated bank-time fixed effects capture idiosyncrasies in banks' business conditions. However, the methodology also allows the bank-time fixed effects to pick

\footnotetext{
${ }^{5}$ See Amiti and Weinstein (2011), Chor and Manova (2012) and Paravisini et al. (2015).

${ }^{6}$ On the real effects of financial shocks see also Peek and Rosengren (1997), Peek and Rosengren (2000) and Ashcraft (2005). For a seminal paper on the Great Depression see Bernanke (1983). For papers on the role of global banks in international spillover effects, see, e.g., Bruno and Shin (2015), Cetorelli and Goldberg (2012), Kalemli-Ozcan et al. (2013), and Ongena et al. (2013).

${ }^{7}$ We propose a normalization to make bank shocks comparable across time, obtain bank shocks separately for each country, systematically dropping information on similar countries to counter endogeneity concerns, and demonstrate how sorting into markets can be addressed. We discuss the details of our innovations after introducing the methodology.

${ }^{8}$ These data were first used in Niepmann and Schmidt-Eisenlohr (2013).
} 
up strategic decisions by bank managers to expand or contract the trade finance business.

Changes in the supply of LCs can have an effect on trade because exporters and importers cannot easily switch between different banks when they want to settle a transaction based on this instrument. An LC is a means to reduce the risk of a trade, which works as follows: The importer asks a bank in her country to issue an LC. This letter is sent to the exporter. It guarantees that the issuing bank will pay the agreed contract value to the exporter if a set of conditions is fulfilled. ${ }^{9}$ In addition, a bank in the exporter's country typically confirms the LC, whereby the confirming bank commits to paying if the issuing bank defaults. Because banks need to work with correspondent banks abroad, the provision of LCs implies significant fixed costs for banks so that the business is highly concentrated with only a few large players. Also, banks learn about the credit- and trustworthiness of their clients over time, and such information is not easily transferable. These factors should make it hard for a firm to switch to another bank when its home bank does not provide the service. When firms are not willing to trade without an LC or adjust quantities because expected profits from trading under alternative payment forms are lower, a reduction in the provision of LCs by a single bank has an effect on exports.

The identification strategy pursued in this paper exploits the variation in the importance of banks as providers of LCs across countries. The same reduction in the supply of LCs by a bank should have a bigger effect in markets where the bank has a larger share of the trade finance business. Accordingly, the shock to bank $b$ at time $t$ is weighted by the market share of bank $b$ in country $i$ at time $t-2$, and these weighted shocks are summed over all banks in the sample. The resulting country-time specific shocks are used to predict exports.

The baseline specification tests whether country-level trade finance supply shocks explain the variation in export growth rates controlling for a common time effect and a countryspecific trend in the export growth rate. We find statistically and economically significant effects. A country-level shock of one standard deviation decreases exports, on average, by 1.5 percentage points. We show that below median shocks have larger effects than above median shocks in line with Amiti and Weinstein (2011), which indicates that our identification comes mostly from reductions in the supply of trade finance. Export growth is mostly affected through adjustments in quantities, lending support to the hypothesis that there is trade finance rationing.

The identifying assumption that establishes a causal link between supply shocks and ex-

\footnotetext{
${ }^{9}$ For example, the issuing bank may promise to pay upon receipt of shipping documents.
} 
ports is that there are no time-varying unobserved country-specific factors that are correlated with both export growth and supply shocks. Given our methodology, two conditions need to hold. First, the estimated shock to the supply of LCs by bank $b$, based on information from countries other than country $i$, is not correlated with changes in the demand for trade finance and, hence, growth in exports to country $i$. Second, banks with positive shocks to their supply of trade finance in period $t$ do not sort, at time $t-2$, into markets with positive deviations from trend export growth in period $t$.

We address the first concern in several different ways. First, we systematically exclude countries from the sample on which we estimate the bank-level shocks. In one case, we use information on larger U.S. export destinations to explain export growth to the smaller export destinations. In another exercise, we search for the nearest neighbors of a country in terms of the structure of its U.S. imports and construct the country-level supply shocks without information on these nearest neighbors. In both cases, the results are unchanged. Endogeneity of the country-level supply shocks could only arise if banks specialized in some dimension, e.g. in firms or industries, and if banks' trade finance market shares were correlated with the export shares of these firms, industries etc. The described checks make it hard to defend the hypothesis that our results could be generated by demand effects. In addition, we show directly that the specialization hypothesis is not supported by the data.

The second concern is related to sorting. Both Amiti and Weinstein (2011) and Paravisini et al. (2015) rely on the identification assumption that there is no sorting of banks and firms in regard of unobserved trends in their future performance. A key advantage of our estimation strategy is that we can rule out sorting, in our case the sorting of banks into destination markets as described above, because (i) the estimated bank-level shocks are not positively serially correlated and (ii) results are unchanged when different lags of banks' market shares are used to construct the country-level shocks. This strongly suggests that the link found in this paper is indeed causal.

In a quantitative exercise, we evaluate the effect of a negative shock to the trade finance supply of one large bank. A reduction that corresponds to the 10th percentile of the banklevel shock distribution leads to a 1.4-percentage-point decline in total U.S. exports growth. This illustrates that the behavior of a single bank can have an effect in the aggregate due to the high concentration of the business.

Another key result of this paper is that banks can affect export patterns. Because banks specialize in confirming and issuing LCs in certain markets, a reduction in the supply of 
LCs by a single bank has asymmetric effects across destination countries. We show that a shock of the same size to two different banks affects exports to different regions of the world differentially, depending on the markets in which each bank specializes. Hence, the patterns of banks' global activities determine to which markets shocks are transmitted.

In addition, we find that the effect of LC supply shocks are heterogeneous across export destinations and over time. Exports to smaller and poorer destinations where fewer U.S. banks are active decline more when banks reduce their supply of trade finance. We also present evidence that the effect of reductions in the supply of trade finance are stronger during times of financial distress. In a crisis period, the effect more than doubles compared to normal times with a beta coefficient of 13.5 percent. These findings can be explained as follows. Firms use LCs more intensively and are less willing to trade without them when exporting to riskier markets and when economic uncertainty is high. At the same time, it is more difficult for firms to switch to other banks. There are fewer banks active in smaller markets. Moreover, banks may be less willing to expand to new markets and less able to obtain liquidity or to take on more risk during a financial crisis. Together the presented results suggest that the $\mathrm{LC}$ channel is quantitatively relevant and that a lack of trade finance can constrain exports especially to the smaller and poorer countries.

The key contribution of our paper compared to earlier works on financial shocks and trade is to show that reductions in the supply of trade finance reduce exports through the risk channel, and that this risk channel is more important during times of financial distress and for exports to small and poor countries. Using Japanese matched bank-firm data from 1990 to 2010, Amiti and Weinstein (2011) show that if a bank has a negative shock to its market-to-book value, a firm that lists this bank as its main bank has a drop in exports that is larger than the observed drop in domestic sales. While the authors establish a general link between banks and trade, they cannot test for the heterogeneous effects of shocks across export destinations and cannot directly distinguish between different transmission channels due to data limitations. ${ }^{10}$ Paravisini et al. (2015) focus on the working capital channel using matched bank-firm data from Peru. Exploiting heterogeneity in the exposure of banks to foreign funding shocks, they find that credit supply shocks reduced exports during the recent financial crisis but that this effect was not asymmetric across export destinations. ${ }^{11}$ Del Prete

\footnotetext{
${ }^{10}$ Indirect evidence for the risk channel is provided: exports of firms that have affiliates drop less than exports of stand-alone firms.

${ }^{11}$ This highlights that the distinction between the working capital channel and the LC channel matters. A reduction in the supply of bank guarantees should have a different effect on trade than a reduction in the supply of general loans. First, working capital needs are independent of payment risk, whereas the risk that
} 
and Federico (2014) employ Italian matched bank-firm data that allow them to distinguish between general loans, trade-related loans and guarantees. The authors report that Italian banks mainly reduced their supply of general loans and that this, but not reductions in trade finance per se, lowered Italian exports during the Great Recession. A drawback of that study is the lack of export data by destination so that the authors cannot analyze effects across export markets.

Three other papers also focus on the risk channel. Ahn (2013) analyzes the effect of bank balance-sheet shocks on the provision of LCs in 2008/2009 in Colombia. Similar to the results in this paper, he finds that bank balance-sheet items predict the variation in bank-level LC supply. He does not test for the effect of supply shocks on aggregate trade flows, however. Van der Veer (forthcoming) studies the role of trade credit insurance and finds a relationship between the supply of insurance by one large insurer and aggregate trade flows. Auboin and Engemann (2014) exploit data on export insurance from the Berne Union to analyze the effect of insurance on trade. Hale et al. (2013) document that an increase in bank linkages between countries is associated with larger bilateral exports, conjecturing that banks mitigate export risk.

The paper is also related to the literature on financial development and trade patterns. Beck (2003) and Manova (2013) show that differences in financial development can generate comparative advantage, confirming a theoretical point first made by Kletzer and Bardhan (1987).

The paper is structured as follows. Sections 2 and 3 give background information on banks' role in trade finance and the data, respectively. Section 4 discusses the empirical strategy. Section 5 presents the results and robustness checks. Section 6 quantifies the aggregate effects of LC supply shocks. Section 7 concludes.

the importer defaults determines whether an exporter demands an LC. Moreover, working capital loans are fungible and firms can internally reallocate available funds. LCs, in contrast, are destination specific and can only be obtained from a small number of banks. 


\section{A Primer on Trade Finance and Letters of Credit}

\subsection{The role of banks in facilitating trade}

When exporters and importers engage in a trade, they have to agree on who finances the transaction and who bears the risk. Banks help both with financing and with mitigating the risk. The most common payment form in international trade is an open account. In this case, the exporter produces first and the importer pays after receiving the goods. The exporter pre-finances the working capital, either with funds out of her cash flows or through a loan from a bank. Moreover, she bears the risk that the importer will not pay after receiving the goods. ${ }^{12}$

To address this commitment problem, banks offer LCs. Figure 1 illustrates how they work. A bank in the importing country issues an LC, which is sent to the exporter. The LC guarantees that the issuing bank will pay the agreed contract value to the exporter if a set of conditions is fulfilled. These conditions typically include delivering a collection of documents to the bank, e.g., shipping documents that confirm the arrival of the goods in the destination country. In most cases, a bank in the exporting country is also involved in the LC transaction. Because there is still a risk that the issuing bank will default on its obligation, the exporter can ask a bank in her country to confirm the LC. The confirming bank thereby agrees to pay the exporter if the issuing bank defaults. To the extent that banks can monitor the transaction, the commitment problem is resolved with an LC, since the exporter is paid only after delivering the goods and the importer commits to paying by making her bank issue an LC. ${ }^{13}$

International trade is riskier than domestic sales because contracts are harder to enforce across borders. In addition, less information about the reliability of trading partners may be available. Accordingly, LCs are widely used in international trade and are employed to a much smaller extent for domestic sales. Data from the SWIFT Institute on LCs show this.

\footnotetext{
${ }^{12}$ Alternatively, the exporter and the importer can agree on cash-in-advance terms. Then, the importer pays the exporter before receiving the goods. In that case, financing is done by the importer who also bears the risk that the exporter may not deliver.

${ }^{13} \mathrm{An}$ LC could be defined as a payment on open account with a bank guarantee. It is similar to pure open account in that the exporter still needs to pre-finance the transaction and gets paid only after confirmation of delivery. It differs in that the risk the exporter has to bear is reduced by the guarantee of the bank. Moreover, the importer has to pay a fee to her bank in advance and the requested guarantee might reduce her available credit lines. The financial costs of an LC are therefore higher. See Schmidt-Eisenlohr (2013), Antràs and Foley (forthcoming) and Hoefele et al. (2013) for a more detailed discussion of different payment forms.
} 
In 2012, around 92 percent of all LCs in support of U.S. sales were related to exports and only 8 percent to domestic activity. ${ }^{14}$ Essentially all letters of credit supporting U.S. exports are denominated in U.S. dollars.

\subsection{Market structure of the business}

The trade finance business and, in particular, the market for bank guarantees is highly concentrated. Niepmann and Schmidt-Eisenlohr (2013) and Del Prete and Federico (2014) present details on the market structure for the U.S. and Italy, respectively. In 2012, the top 5 banks accounted for 92 percent of all trade finance claims in the U.S. In Italy, the business is similarly concentrated. Only ten Italian banks extend trade guarantees.

The high concentration is likely due to high fixed costs. When U.S. banks confirm an LC, they need to work with banks abroad and have knowledge of their credit- and trustworthiness. U.S. banks also have to do background checks on their customers to comply with due diligence requirements and anti-money laundering rules before they can engage in any business abroad. They also need to be familiar with the foreign market and the legal environment there. Such knowledge is costly to acquire and not easily transferable.

Due to the presence of information asymmetries, the importance of relationships, and the resulting high concentration of the market, it should be difficult for a firm to switch to another bank when its home bank refuses to confirm or issue an LC. Note that there is no alternative method that reduces commitment problems to the same degree. Trade credit insurance, another option for exporters, does not reduce the risk but instead shifts it to another agent, the insurer. ${ }^{15}$ As a consequence, the price of insurance should increase more with destination country risk than the price of LCs, and insurance may be unavailable in the most risky destinations. If an LC cannot be obtained and trade insurance is very costly or cannot be bought, importers and exporters may not be willing to trade. Then a reduction in the supply of LCs has an effect on trade. ${ }^{16}$

\footnotetext{
${ }^{14}$ These calculations are based on quarterly information about the number of SWIFT MT700 messages that were received by U.S. banks.

${ }^{15}$ When issuing or confirming an LC, banks actively screen documents and manage the conditional payment to the exporter and thereby resolve the commitment problem. Trade credit insurance also implies a guarantee of payment but has no direct effect on the underlying commitment problem. This difference can best be seen in a model with risk-neutral firms as in Schmidt-Eisenlohr (2013). There, firms demand LCs but have no reason to buy trade credit insurance.

${ }^{16}$ Note that there is an effect on trade even if an alternative contract is chosen by a firm. It follows from revealed preferences that whenever LCs are used, other payment forms generate weakly lower profits. Hence, a reduction in the supply of LCs can affect both the intensive and the extensive margins of trade. Quantities
} 


\subsection{Public provision of trade finance}

Most multinational development banks today run large trade finance programs, with the view that the private sector may not meet the demand. These programs were small at first and often targeted to the least developed countries. However, they were expanded substantially during the 2008/2009 crisis and now also cover many emerging economies. ${ }^{17}$ The Global Trade Finance Program of the International Finance Organization, which is a part of the World Bank group, for example, now has a $\$ 5$ billion program that mostly confirms letters of credit through participating private banks. ${ }^{18}$

Surveys of banks conducted by the International Monetary Fund and the International Chamber of Commerce support the view that the supply of trade finance can constrain international trade. Asmundson et al. (2011) report that 38 percent of large banks said in July 2009 that they were not able to satisfy all their customer needs and 67 percent were not confident that they would be able to meet further increases in trade finance demand in that year. Greater trade finance constraints may also come from increases in prices. According to the same survey, letter of credit prices increased by 28 basis points (bps) over the cost of funds from 2007 q4 to 2008 q4 and by another 23 bps over the cost of funds between 2008 q4 and 2009 q2. ${ }^{19}$ Banks also reported that their trade-related lending guidelines changed. Every large bank that tightened its guidelines said that it became more cautious with certain countries. Thus, constraints may differ by destination country. As we will show in the next sections, this survey evidence is consistent with the results presented in this paper.

\section{Data Description}

The data on trade finance used in this paper are from the Country Exposure Report (FFIEC 009). U.S. banks and U.S. subsidiaries of foreign banks that have more than $\$ 30$ million in total foreign assets are required to file this report and have to provide, country by country, information on their trade-finance-related claims with maturity of one year and under.

decline as trade finance costs, which represent variable trade costs, go up. If costs become sufficiently large, trade becomes unprofitable.

${ }^{17}$ In 2009 , in the wake of the great recession, the G20 agreed on a $\$ 250$ billion dollar program over two year to support trade finance. See G20 (2009).

${ }^{18}$ See IFC (2012) for more details.

${ }^{19}$ Similar results are obtained in the ICC survey. 42 percent of respondents in a 2009 survey report that they increased their prices for commercial letters of credit issuance, whereas 51 percent left prices unchanged and 7 percent decreased them. LC confirmation also got more expensive. 58 percent of respondents report that they increased their prices, while only 2 percent lowered their fees. 
Claims are reported quarterly on a consolidated basis; that is, they also include the loans and guarantees extended by the foreign affiliates of U.S. banks. The sample covers the period from the first quarter of 1997 to the second quarter of $2012 .^{20}$

The statistics are designed to measure the foreign exposures of banks. This information allows regulators to evaluate how U.S. banks would be affected by defaults and crises in foreign countries. Therefore, only information on the claims that U.S. banks have on foreign parties is collected. Loans to U.S. residents and guarantees that back the obligations of U.S. parties are not recorded. While we can rule out based on the reporting instructions that letters of credit in support of U.S. imports or pre-export loans to U.S. exporters are included, it is conceivable that several trade finance instruments that support either U.S. exports, U.S. imports, or third-party trade constitute the data. ${ }^{21}$ Niepmann and Schmidt-Eisenlohr (2013) provide a detailed discussion and exploration of the data and we provide a summary of the findings here. Their analysis indicates first, that banks' trade finance claims reflect trade finance in support of U.S. exports, and second, that the main instrument in the data are letters of credit.

Before presenting in detail evidence for these two conjectures, we explain the link between the reported claims and export values. Suppose that a U.S. bank confirms a letter of credit issued by a bank in Brazil. Then the U.S. bank would suffer a loss in the event that the Brazilian bank defaults on its obligation to pay. Accordingly, the U.S. bank reports claims vis-à-vis Brazil equivalent to the value of the letter of credit. The value of the letter of credit, in turn, is determined by the value of the goods that the Brazilian firm buys from the U.S exporter. So there is a direct link between claims and the value of the exported goods. Similarly, if an affiliate of a U.S. bank in Brazil issues a letter of credit to a Brazilian importer, the affiliate backs the obligations of the foreign importer. Accordingly, the parent bank, which files the Country Exposure Report on a consolidated basis - meaning that the claims of its affiliate appear on its balance sheet but not the claims on its affiliate, reports the contract value as claims vis-à-vis Brazil. Since the average maturity of a confirmed letter of credit is 70 days (see ICC (2013)), the stock of claims at the end of a quarter is highly correlated with the flow of exports in that quarter; thus, we compare quarterly stocks with

\footnotetext{
${ }^{20}$ Until 2005, banks' trade finance claims are reported on an immediate borrower basis; that is, a claim is attributed to the country where the contracting counter-party resides. From 2006 onward, claims are given based on the location of the ultimate guarantor of the claim (ultimate borrower basis). This reporting change does not appear to affect the value of banks' trade finance claims in a systematic way, so we use the entire time series without explicitly accounting for the change. See http://www.ffiec.gov/ for more details.

${ }^{21}$ Table 1 summarizes which instruments could be included based on the reporting instructions.
} 
quarterly trade flows. The data on U.S. trade in goods used in this paper are from the IMF Direction of Trade Statistics.

We now turn to the evidence that the FFIEC 009 data largely reflect letters of credit in support of U.S. exports. Consider columns (1) to (3) of table 2, which present the results of OLS regressions, in which the log of banks' total trade finance claims in quarter $t$ in country $c$ is regressed on the $\log$ of imports from country $c$, the $\log$ of exports to country $c$ and total non-U.S. imports and exports of country $c$ at time $t$. The second column includes time fixed effects. The third column has both time and country fixed effects. Standard errors are clustered at the destination country level. The estimated coefficients show that banks' trade finance claims are primarily driven by U.S. exports. While the point estimates associated with U.S. imports, non-U.S. imports and non-U.S. exports are small and insignificant, the coefficient of U.S. exports is large and significant at a 1 percent significance level throughout. The coefficient in column (1) suggests that if U.S. exports rise by 10 percent, banks' trade finance claims increase by 8.6 percent.

A comparison with data from the SWIFT Institute suggests that the main instrument in the FFIEC009 data are letters of credit. SWIFT provides a communications platform to exchange standardized financial messages, which is used by the vast majority of banks in the world. When a letter of credit transaction occurs, the issuing bank in the importer's country sends a SWIFT MT700 message to the confirming bank in the exporter's country, specifying the terms of the letter of credit and the parties involved. The SWIFT Institute provided us with the number of monthly MT700 messages received by banks located in the U.S. from 2002 to 2012 by sending country. To the extent that banks' trade finance claims reflect letters of credit, there should be a close link between the quarterly value of bank claims and the number of SWIFT messages sent within a quarter. Columns (4) to (6) of table 2 show correlations between the two variables. The number of SWIFT messages received by U.S. banks is a strong predictor of banks' trade finance claims controlling for U.S. exports as well as time and country fixed effects. ${ }^{22}$ A rise in the number of SWIFT messages by 10 percent increase banks' trade finance claims by 6 percent according to column (4) of table 2 . We also have information on the value of the letters of credit received by U.S. banks from the fourth quarter of 2010 onward. In that quarter, the total value of SWIFT messages accounts for 67 percent of banks' total trade finance claims, which indicates again that the claims data

\footnotetext{
${ }^{22}$ Note that Niepmann and Schmidt-Eisenlohr (2013) also include LC messages sent by U.S. banks to country $i$ in the regressions, which reflect LCs issued to U.S. firms that import from origin $i$. This variable has zero explanatory power. LCs in support of U.S. imports are not in the data.
} 
mostly captures LCs.

In addition to the arguments made above, Niepmann and Schmidt-Eisenlohr (2013) show that the claims data behaves in many respects like the MT700 messages. For example, the use of letters of credit by U.S. exporters is expected to be hump-shaped in destination country risk and the authors find that this relationship holds for both banks' trade finance claims and SWIFT MT700 messages. Thus everything points to letters of credit being the single most important instrument in the data. If bank claims captured other trade finance instruments to a substantial degree, the analysis in this paper would still be valid. The only other instrument in support of U.S. exports that can be included in the data are pre-import loans to foreign firms. ${ }^{23}$ To the extent that this is the case, the estimated shocks would not necessarily only reflect shocks to the supply of letters of credit but also to credit provided by U.S. banks to foreign importers.

Figure 2 depicts the evolution of U.S. exports and banks' trade finance claims over time, as shown in Niepmann and Schmidt-Eisenlohr (2013). Trade finance claims peaked in 1997/1998 during the Asian crisis and again during the financial crisis in 2007-2009. ${ }^{24}$ Since 2010, claims have increased considerably, which is likely due to the low interest rate environment and the retrenchment of European banks from this U.S.-dollar-denominated business, allowing U.S. banks to gain their market shares. The graph clearly indicates that trade finance plays an important role for U.S. firms. In 2012, total trade finance claims of U.S. banks amounted to roughly 20 percent of U.S. exports.

Figure 3 shows the distribution of trade finance claims and U.S. exports across world regions in the second quarter of 2012. Regions are ranked in descending order from the left to the right according to their shares in total trade finance. The upper bar displays the trade finance shares of the different regions. The lower bar illustrates regions' shares in U.S. exports. While around 50 percent of U.S. exports go to high income OECD countries, banks' trade finance claims in these countries only account for around 20 percent. In contrast, East Asia and the Pacific only receive 11 percent of U.S. exports, but this region's share in trade finance is twice as large. The figure indicates substantial variation in the extent to which exporters rely on trade guarantees across regions and destination countries, which could lead to asymmetric effects of reductions in the supply of letters of credit. We explore asymmetries

\footnotetext{
${ }^{23}$ Credit to U.S. firms cannot be in the data given the reporting instructions. Forfeiting and factoring, which also reduce the risk of a transaction for the exporter, could be included but statisticians at the New York Fed tell us that this is not likely to be the case since U.S. banks are not very active in this business.

${ }^{24}$ Evidence from Italy and IMF surveys also suggests that trade finance expanded during the recent financial crisis. See Del Prete and Federico (2014) and Asmundson et al. (2011).
} 
in more detail in section 5 .

\section{Empirical Approach}

\subsection{Estimating trade finance supply shocks}

In this section, we discuss the empirical strategy to identify the causal effect of letter-of-credit supply shocks on exports. The challenge in establishing a causal link is to obtain a measure of supply shocks that is exogenous to the demand for LCs. Because we have information on the trade finance claims of U.S. banks by destination country that varies over time, we can estimate time-varying idiosyncratic bank-level supply shocks from the data. ${ }^{25}$ In line with Greenstone et al. (2014) and Amiti and Weinstein (2013), we estimate the following equation: ${ }^{26}$

$$
\Delta t f_{b c t}=\frac{t f_{b c t}-t f_{b c t-1}}{t f_{b c t-1}}=\alpha_{b t}+\beta_{c t}+\epsilon_{b c t},
$$

where $t f_{b c t}$ corresponds to the trade finance claims of bank $b$ in country $c$ and quarter $t$. Trade finance growth rates are regressed on bank-time fixed effects $\alpha_{b t}$ and on country-time fixed effects $\beta_{c t}$. If all $\beta_{c t}$ 's were included in the regression together with all $\alpha_{b t}$ 's, the $\alpha_{b t}$ 's and $\beta_{c t}$ 's would be collinear so one fixed effect must be dropped from the regression in each quarter. Without an additional step, the estimated bank-time fixed effect would vary depending on which fixed effect serves as the base category in each period and is omitted from the regression. To avoid this, we regress the estimated bank-time fixed effects on time fixed effects and work with the residuals $\hat{\alpha}_{b t}$ in place of the estimated $\alpha_{b t}$ 's. This normalization sets the mean of $\hat{\alpha}_{b t}$ in each period $t$ to zero and thereby makes it irrelevant which fixed effects are left out when equation 1 is estimated.

The obtained bank-time fixed effects $\hat{\alpha}_{b t}$ correspond to idiosyncratic bank shocks. By construction, they are independent of country-time specific factors related to the demand for trade finance (and, hence, export growth) that affect all banks in the sample in the same way. To further address the concern that bank shocks might pick up demand effects, bank shocks are estimated for each country separately: the bank shock $\hat{\alpha}_{i b t}$ for country $i$ is

\footnotetext{
${ }^{25}$ Previous works on the effect of finance on trade use proxy variables to identify shocks. Amiti and Weinstein (2011) use banks' market-to-book values. Paravisini et al. (2015), Del Prete and Federico (2014) and Ahn (2013) exploit the variation in banks' funding exposures.

${ }^{26}$ Based on a cross-section observed at two points in time, Greenstone et al. (2014) estimate a model in log differences to obtain bank shocks. Amiti and Weinstein (2013) use a time-series, as we do, but impose adding-up constraints on the shocks.
} 
obtained by estimating equation 1 without including observations of country $i$. Therefore, $\hat{\alpha}_{i b t}$ reflects growth in trade finance claims by bank $b$ in quarter $t$ based on changes in claims in all countries except country $i .^{27}$

The normalized bank-level supply shocks $\hat{\alpha}_{i b t}$ are used to construct country-specific supply shocks as follows:

$$
\operatorname{shock}_{i t}=\sum_{b}^{B} \phi_{i b t-2} \hat{\alpha}_{i b t}
$$

where $\phi_{i b t-2}=\frac{t f_{i b t-2}}{\sum_{b}^{B} t f_{i b t-2}}$. Thus, bank supply shocks are weighted by the share of bank $b$ in the total trade finance claims of country $i$ at time $t-2$ and are summed over all banks in the sample. In section 5.4, we show that results also hold when market shares are lagged by an alternative number of quarters or are averaged over several preceding periods.

The effect of trade finance supply shocks on exports is estimated based on the following equation:

$$
\Delta X_{i t}=\frac{X_{i t}-X_{i t-1}}{X_{i t-1}}=\gamma \operatorname{shock}_{i t}+\delta_{t}+\delta_{i}+\eta_{i t},
$$

where $X_{i t}$ denotes U.S. exports to country $i$ at time $t$. Export growth rates are regressed on the constructed country-level supply shocks as well as on country fixed effects and time fixed effects. The key coefficient of interest is $\gamma$.

Under the assumption that the computed country supply shocks are not systematically correlated with unobserved characteristics that vary at the time-country level and are correlated with exports, $\gamma$ corresponds to the causal effect of trade finance supply shocks on export growth. Expressed in formulas, the identification assumption is: $E\left(\left(\sum_{b}^{B} \phi_{i b t-2} \hat{\alpha}_{i b t}\right) \eta_{i t}\right)=0$. Given the presented strategy, the assumption is satisfied if two conditions hold. First, the estimated shock to the supply of LCs by bank $b$, based on information from countries other than country $i$, is not correlated with changes in the demand for trade finance and, hence, growth in exports to country $i$. Second, banks with positive shocks to their supply of trade finance in period $t$ do not sort, at time $t-2$, into markets with positive deviations from trend export growth in period $t$. We discuss possible violations of these conditions in detail in section 5.4. The biggest endogeneity concern that the reader might have is that the estimated bank shocks pick up changes in the supply of or demand for U.S. exports. We

\footnotetext{
${ }^{27}$ As indicated, it does not matter which fixed effects are dropped in the estimation of equation 1. In practice, we estimate equation 1 for all countries except Canada and exclude Canada fixed effects. In the regression to obtain bank-time fixed effect that apply to Canada, we exclude France fixed effects. While we estimate equation 1159 times, dropping one country from the sample actually does not matter. Results are essentially identically if we work with bank-time fixed effects obtained from estimating equation 1 only once based on a sample that includes all countries.
} 
present a battery of exercises that strongly suggest that our results come in fact from shocks to the supply of trade finance. We also show that sorting as a driver of our findings can be excluded.

Before turning to the description of the data, we also want to discuss the interpretation of $\gamma \cdot \gamma$ captures the effect of a trade finance supply shock to country $i$ on export growth to country $i$ relative to export growth in all other countries. A positive shock to the supply of trade finance for exports to country $i$ may redirect exports to country $i$, meaning that exports to country $i$ increase at the expense of exports to other countries. Because of such trade diversion, the estimate of $\gamma$ should be seen as an upper bound for the direct effect of trade finance supply shocks on exports to country $i .^{28}$

\subsection{Description of the sample}

U.S. banks have trade finance claims in practically all countries of the world but only a few out of all banks that file the FFIEC009 report have positive values. For example, in the first quarter of 2012, 18 banks had positive trade finance claims in at least one country whereas 51 banks reported none. Three banks had positive trade finance claims in more than 70 countries while seven banks were active in less than five countries. Over the sample period, banks drop in and out of the dataset and acquire other banks. To account for acquisitions, the trade finance growth rates are calculated in the period of an acquisition based on the sum of the trade finance claims of the acquired bank and the acquiring bank in the previous period. The same adjustment is made when the bank shares $\phi_{i b t-2}$ are calculated. If a bank acquired another bank at time $t$ or $t-1$ we use the country share of the two banks added up to compute bank shares.

Bank supply shocks are estimated on a sample in which observations are dropped for which $t f_{b c t}$ is zero. If $t f_{b c t-1}=0$, trade finance growth rates in quarter $t$ have to be dropped because they go to infinity. To make the estimation less prone to outliers and keep things symmetric, we also drop negative growth rates of 100 percent. For 8.5 percent of all observations $t f_{b c t}=0$. The total claims associated with these observations is small, adding up to a little more than one percent of the value of total claims in the data. ${ }^{29}$ We also drop the first and 99th percentiles of the trade finance growth rate distribution based on

\footnotetext{
${ }^{28}$ Any standard general equilibrium trade model predicts this kind of trade diversion, that is, trade flows to other countries $j \neq i$ weakly decrease when trade frictions to country $i$ decrease.

${ }^{29}$ The share is based on the number of non-missing observations for which it is not the case that claims are zero both in period $t$ and in period $t-1$.
} 
the remaining observations, further mitigating the influence of outliers. The dataset used to estimate equation 1 and obtain the bank-time fixed effects has 32,256 observations, covers the period from 1997 q2 to 2012 q2 and includes 107 banks as well 159 countries. ${ }^{30}$

\subsection{Heterogeneity and persistence in banks' market shares}

The empirical strategy in this paper requires that the importance of single banks be heterogeneous across destination markets. Otherwise, all countries would be subject to the same shock and we would not be able to identify effects. In addition, it is essential that banks have stable market shares over time, because we use lagged values to compute country shocks. If banks' market shares were very volatile, then lagged values would not contain useful information about the degree to which bank-level supply shocks affect different countries.

The upper panel of table 3 shows summary statistics of $\phi_{b i t}$, the share of bank $b$ in the total trade finance claims of all U.S. banks in country $i$ at time $t$, at different points in time. There is substantial heterogeneity at every date. The average bank share increased from 2000 until 2012, consistent with the observed reduction in the number of banks active in the trade finance business. ${ }^{31}$ Bank shares range from below 0.1 percent to 100 percent. The standard deviation is 27 percent in the first quarter of 2012.

Persistence in banks' market shares can be reflected in both the intensive and the extensive margin. On the one hand, a bank should account for a stable fraction of a country's overall trade finance supply over time (intensive margin). On the other hand, there should be no frequent exit and entry of banks into markets (extensive margin).

We check whether bank shares are persistent in two different ways. First, we regress the market share $\phi_{i b t}$ of bank $b$ in country $i$ at time $t$ on country-bank fixed effects. These fixed effects alone explain more than 77 percent of the variation in bank shares, which implies that there is much cross-sectional variation in banks' market shares but little time variation. Second, we regress the current market share $\phi_{i b t}$ on its lagged values. Without adjusting for mergers and acquisitions, the one-quarter lagged bank share explains around 84 percent of the variation in the current share, as shown in table $4 .^{32}$ Two-period lagged

\footnotetext{
${ }^{30}$ Given that we always drop one country from the sample to estimate equation 1 , the sample is slightly different and smaller in each estimation and includes only 158 countries.

${ }^{31}$ Changes in banks' market shares over time are slow but substantial. Therefore, we cannot use market shares in the beginning of the sample period and keep them constant over time to obtain country-level shocks.

${ }^{32}$ If we adjusted for M\&As, then persistence would be even higher.
} 
values, which are used to construct country supply shocks, still explain around 77 percent of the variation (see the $R^{2}$ in column (2)). Column (3) includes bank fixed effects, showing that the high correlation between current and lagged market shares does not come from systematic differences in size across banks.

A similar exercise can be conducted for the number of banks $n_{i t}$ that are active in a given market $i$. The lower panel in table 3 shows statistics for this variable. The number of banks operating in a given country fell over the sample period. In the first quarter of 2012, there were at most 14 banks active in a single country. The mean of the variable is 3.6 and the standard deviation is 2.8 in the same quarter.

A regression of the number of banks in country $i$ at time $t$ on country and time fixed effects accounts for more than 76 percent of the variation. As an alternative, similar to before, the number of banks in period $t$ is regressed on its lagged values. Table 5 displays the results. The two-quarter lagged number of active banks explains approximately 92 percent of the variation in this variable.

\subsection{Exploring the estimated bank-level shocks}

There are a total of 107 different banks in the sample for which we obtain trade finance supply shocks. In the third quarter of 1997, bank shocks for 54 different banks are estimated, down to 18 banks in the second quarter of 2012 due to consolidation in the banking sector. In total, we estimate 325,389 time-country-varying bank shocks from 1997 q2 until 2012 q2. ${ }^{33}$ Figure 4 shows the distribution of bank shocks, which exhibits significant variation. Table 6 provides the corresponding summary statistics. Figure 5 displays the mean and median normalized bank shock as well as the standard deviation of the bank shocks over time. Note that the mean is by construction equal to zero in each quarter.

To check whether the bank shocks, which are estimated without the use of information on country $i$, predict trade finance growth in country $i$, we run the following regression:

$$
\Delta t f_{i b t}=\hat{\alpha}_{i b t}+\xi_{t}+\xi_{i}\left(+\xi_{i t}\right)+\eta_{i b t}
$$

where $\Delta t f_{i b t}$ represents the growth rate of the claims of bank $b$ in country $i$ in quarter $t$ observed in the data. $\hat{\alpha}_{i b t}$ is the normalized bank shock of bank $b$ at time $t$ that was

\footnotetext{
${ }^{33}$ Recall the bank-time fixed effects are estimated for 159 different countries, so for each estimation of equation 1 , we estimate around 2,100 bank-time fixed effects.
} 
estimated based on equation 1 without including $\Delta t f_{i b t}$ in the sample. The regression results are displayed in table 7 . The first column excludes fixed effects; the second column includes both time fixed effects $\xi_{t}$ and country fixed effects $\xi_{i}$. The third column controls for countrytime fixed effects $\xi_{i t}$. Standard errors are clustered at the bank-time level. The coefficient on the bank shock is highly significant and positive in all three columns. This shows that the estimated bank shocks based on developments in other countries have strong predictive power for the actual growth of trade finance claims of bank $b$ in country $i$ at time $t$, although they do not explain much of the variation as the low $R^{2}$ in column (1) indicates.

Next, we investigate whether bank supply shocks are serially correlated. The main goal of this exercise is to document that there is no positive serial correlation. We will use this result in the robustness section 5.4. Table 8 displays results from a regression of the average bank shock $\bar{\alpha}_{b t}$, which corresponds to the value of $\hat{\alpha}_{i b t}$ averaged over all countries, on its lagged values and time fixed effects. The regression in column (1) includes only the one-quarter lagged bank shock. In column (2), the two-quarter lagged shock is added as a regressor. Column (3) includes one- to four-quarter lagged values of $\bar{\alpha}_{b t}$. The coefficients of the one-quarter lagged bank shock is significant and negative but small. ${ }^{34}$

Finally, we check whether bank shocks are correlated with meaningful bank-level variables. ${ }^{35}$ Banks allocate funding to business lines and may cut funding as overall conditions worsen. Because trade finance is short term and contracts are liquidated within a few months or even weeks, trade finance can be quickly reduced to shrink banks' overall balance sheet, reduce exposures and improve liquidity. However, banks may also take strategic decisions to grow or contract trade finance for other reasons. Thus, the estimated bank-level shocks may also capture changes in the supply of trade finance that are not closely linked to the current health of the bank. Banks may, for example, decide to contract their operations with foreign entities to refocus on core activities or when due diligence requirements change. ${ }^{36}$ There is in fact anecdotal evidence that, due to recently elevated due diligence requirements, some banks have reduced their cooperation with foreign banks. Moreover, European banks withdrew from the international trade finance business after the European sovereign debt crisis, which allowed U.S. banks to grow. The empirical strategy pursued in this paper allows us

\footnotetext{
${ }^{34}$ The negative serial correlation appears to be particularly strong after 2009. The coefficient on the lagged shock is not significant during the crisis period.

${ }^{35}$ Balance-sheet information for banks in the sample comes from the Y-9C and FFIEC 031 reports. Credit default swap spreads are taken from Markit.com.

${ }^{36}$ See Working Group on Trade, Debt and Finance (2014) for a summary of recent developments in trade finance after the $2007 / 2008$ financial crisis.
} 
to capture changes in banks' supply of trade finance for all of these reasons.

While we would therefore not expect the balance sheet variables to fully predict the estimated bank-level shocks, it is interesting to understand the extent to which they do. To that end, the mean bank shock $\bar{\alpha}_{b t}$ is regressed on deposit growth, loan growth and the credit default swap spread on 6-months senior unsecured debt of bank $b$ at time $t$. Results are displayed in table 9. In all columns, bank and time fixed effects are included and standard errors are clustered at the bank level. ${ }^{37}$ The results in column (1) and (2) of table 9 indicate that the average bank shock is positively correlated with loan growth. Columns (3) and (4) show that it is negatively correlated with banks' credit default swap spreads, an implicit measure of banks' funding costs. The correlations between these bank-level variables and the estimated shocks becomes stronger in the second half of the sample (see columns (2) and (4)). ${ }^{38}$

\subsection{Distribution of country supply shocks}

In a next step, details on the computed country-level supply shocks $\Delta t f_{i t}$ are given. In total, we obtain country shocks for 156 different countries. ${ }^{39}$ Table 6 displays the summary statistics for this variable.

The regressions that are run to estimate the effect of trade finance supply shocks on trade include country fixed effects. Therefore, we control for time-invariant country characteristics that are correlated with export growth and trade finance supply shocks. However, results do not change when country fixed effects are left out as we show in the next section. This is because supply shocks are randomly distributed across countries. To illustrate this, figure 6 plots the distribution of the average value of a dummy variable $d_{i t}$ that takes value 1 if the supply shock to country $i$ in period $t$ is above the period- $t$ median and zero otherwise. In the limit, where time goes to infinity, random assignment would imply that the mean of the dummy goes to 0.5 for every country. In any finite sample, the dummy should be distributed symmetrically around 0.5. Figure 6 shows that this is the case. A correlation between country-level shocks and country characteristics could only arise if banks with above

\footnotetext{
${ }^{37}$ Note that reverse causality should not be a problem because trade finance claims constitute a small fraction of banks' total activities. The median share of trade finance claims in total assets for the banks in our sample is below 1 percent.

${ }^{38} \mathrm{We}$ also included measures of profitability in the regressions, e.g. return on equity and return on assets, but the associated coefficients were not significant.

${ }^{39}$ The number of countries reduces slightly because lagged bank shares are not observed for all countries for which we can obtain bank-level shocks.
} 
or below median shocks were associated with particular countries. Figure 6 indicates that this is not the case and, therefore, that there is no correlation between banks' market shares $\phi_{i b t}$ and the estimated bank-level shocks $\hat{\alpha}_{i b t}$.

In the regressions of export growth on country-level supply shocks (equation 3), countries with a population below 250,000, offshore financial centers and observation in the top and bottom one percentile of the export growth rate distribution are excluded from the sample. ${ }^{40}$ To control for export demand in the destination country, we add a set of variables. This lowers the number of observations further since these variables are not observed for all countries. ${ }^{41}$ However, the properties of the country-level supply shocks are unchanged as the summary statistics for the shock variable of the reduced sample show (see again table 6).

\section{Results}

\subsection{Baseline Results}

Table 10 presents the baseline regression results obtained from estimating equation $3 .{ }^{42}$ Unless stated otherwise, standard errors are bootstrapped for all regressions in this section. ${ }^{43}$ In column (1), export growth is regressed on trade finance supply shocks and time fixed effects. The estimated effect of supply shocks is positive and significant at a 1 percent significance level. The positive coefficient indicates that destination countries that experience larger declines in the supply of trade finance exhibit lower export growth rates. In column (2), several independent variables that control for changes in import demand are included in the regression: GDP growth and population growth, the change in the USD exchange rate of the local currency, and growth in non-U.S. imports of country $i$ in period $t$. In column (3), country fixed effects are added. The inclusion of the additional variables and fixed effects does not affect the magnitude of the estimated coefficient of interest $\gamma$. This confirms that trade finance supply shocks are not systematically correlated with time-invariant country characteristics as found in the previous section or with demand factors.

\footnotetext{
${ }^{40} \mathrm{~A}$ list of countries designated as offshore financial centers can be found in the appendix. Niepmann and Schmidt-Eisenlohr (2013) show that banks' trade finance claims in offshore centers are barely correlated with U.S. exports to these destinations so we drop them since we do not expect a link between trade finance and real activity.

${ }^{41}$ This reduces the number of countries in the baseline sample to 122 .

${ }^{42}$ The $R^{2}$ represents the total $R^{2}$ in all tables in the paper.

${ }^{43}$ Clustering at the country level essentially delivers the same standard errors.
} 
Based on the coefficient of 0.0888 displayed in column (3), a country supply shock of one standard deviation increases export growth by 1.5 percentage points. This corresponds to about 5 percent of one standard deviation of export growth rates. As a reference, table 6 provides summary statistics of export growth rates in the sample. We discuss the magnitude of the effect in more detail in section 6 .

Column (4) of table 10 shows the effect of trade finance supply shocks for above and below median shocks separately. ${ }^{44}$ We compute two sets of country-level shocks using either above median or below median bank-level shocks in each period when aggregating shocks up to the country level. The estimated coefficients indicate that above and below median shocks have asymmetric effects. Only the point estimate of shocks below the quarterly median is statistically significant at a 5 percent level. In addition, it is almost three times larger than the coefficient associated with above median shocks. ${ }^{45}$ This is in line with what one might expect and confirms findings in Amiti and Weinstein (2011). Because a reduction in the supply of LCs typically requires cutting them for existing customers whereas additional supply is more fungible, shocks below the median should have a stronger effect.

To explore which banks are responsible for the effect on exports, we compute supply shocks for the five biggest trade finance suppliers and the remaining banks separately and rerun the baseline regression. ${ }^{46}$ Column (5) of table 10 shows the results. The coefficients on the shocks attributed to the top five banks and the remaining banks are both significant and very similar. It may be surprising that small banks can have an effect in the aggregate. However, smaller banks specialize in certain markets so that they can be large and important for the provision of letters of credit in particular destinations. In column (6), the regression with separate shocks for the top five banks is run on a sample that includes years prior to 2004. Column (7) includes all years beginning with 2004. The sample split highlights that banks other than the top five are responsible for the effect on export growth in the early years of the sample, whereas the top five banks drive the effect in the later years. This finding is likely explained by the fact that the market shares of the top five banks steadily rose over the sample period. Since the banking sector went through a prolonged phase of consolidation, the impact of the top five banks on the total supply of trade finance increased

\footnotetext{
${ }^{44}$ Because we normalize shocks so that their mean is zero, the absolute level of the shocks is not meaningful. Below median shocks are associated with those banks that contracted more or expanded less than the median bank. The opposite holds for above median shocks.

${ }^{45}$ The estimates are not statistically significantly different from each other, however.

${ }^{46}$ We take the five bank with the largest trade finance claims over the sample period and also include merged entities that were separate banks in earlier years.
} 
as smaller banks exited and the trade finance business became more concentrated.

\subsection{Heterogeneous Effects}

In this section, we explore whether effects differ over time and across countries. In table 11, the sample is split into the crisis and the non-crisis period, respectively. The crisis period goes from the third quarter of 2007 to the second quarter of 2009. The non-crisis period includes all other dates. When the export equation (equation 3) is estimated only on the crisis sample, the effect of letter of credit supply shocks is highly significant at a 1 percent significance level and the point estimate of $\gamma$ in column (1) is much larger than for the noncrisis sample in column (2). The shock coefficient of 0.183 in column (1) suggests that a country-level shock of one standard deviation decreases exports by more than 3 percentage points during periods of financial distress. This means that the effect of a reduction in the supply of LCs doubles during a crisis compared to the average effect reported before. To test formally for differences in the effect over time, we include an interaction term between the shock and a dummy variable for the crisis period in column (3) of table 11. The coefficient of the interaction term is significant at a 10 percent level and confirms the differences in magnitudes obtained from the sample split.

The effect of LC supply shocks on export growth does not only vary over time but also across export destinations. In columns (4) and (5) of table 11, the effect of LC supply shocks is estimated based on a sample that only includes small and large export destinations, respectively. We define a country to be small if its log exports over the sample period lies below the sample median. Thus the designation of a country into small or large is constant over time. ${ }^{47}$ Reductions in the supply of LCs only have an effect on small export destinations. While the point estimate of the shock is highly significant and takes a value of 0.189 for small countries in column (4), it is essentially zero and insignificant when only large export destinations are included in the sample in column (5). The difference is confirmed in column (6), in which an interaction term between the shock and a dummy variable for small countries is included, although the coefficient of the interaction is only marginally significant at a 12 percent level. In a next step, we jointly investigate differences over time and across countries. Column (7) includes only small countries and the recent crisis period. In column (8), the export equation is estimated on the full sample and includes now both the crisis interaction and the market size interaction. These additional regressions clearly show that the effect of

\footnotetext{
${ }^{47}$ Countries designated as small are listed in the data appendix.
} 
LC supply shocks on export growth to large countries in normal times is close to zero, while the effect is strongest for exports to small destinations in times of financial distress in the U.S. economy. Then a negative LC supply shock of one standard deviation can lead to a reduction in exports of more than 4 percentage points.

To check whether it is really the size of an export market that leads to differences in the effect across countries, we explore alternative sample splits and introduce interaction terms between the shocks and different variables. The evidence suggests that a crucial determinant of the strength of the effect on export growth is the number of U.S. banks that provide LCs for exports to a given destination country as shown in table 12. In column (1), the export regression is estimated only for countries in which less than five U.S. banks are active in quarter $t-1$. Column (2) shows the results for countries with at least five banks and column (3) is based on the full sample and adds interaction terms. The effect of LC supply shocks on export growth is clearly larger for countries in which less than five banks are active. The interaction term between a dummy for countries with at least five U.S. banks is large, negative and significant at a 5 percent level.

The presented results indicate that export growth to small countries is particularly affected if banks contract their supply of LCs. This is easy to rationalize. First, only a few U.S. banks provide LCs for small destinations. ${ }^{48}$ If one of the banks active in those markets reduces its supply, it is especially difficult for trading partners to find an alternative. Second, selling to destinations with a weak rule of law might not be profitable for the exporter without an LC since the firm's implicit cost of conducting the transaction without a guarantee may be high. At the same time, trade insurance, which is an alternative to an LC, is more likely to be unavailable or very costly.

Our second finding, that the effect of supply shocks is larger during a crisis period, can also be explained by similar factors. During a period of financial distress, trading partners may find it harder to switch to another bank when the core bank refuses to issue or confirm an LC. Other banks may be less willing to expand their trade finance business to a new market during these times, and banks with existing relationships to intermediaries in a foreign country may not be able to obtain liquidity or may not want to add risk to their balance sheets. At the same time, exporters and importer may be more reluctant to trade without an LC as they are more risk averse.

\footnotetext{
${ }^{48}$ Evidence on this is and on how other country characteristics affect the number of active U.S. banks can be found in Table 6 of the working paper version.
} 


\subsection{Price versus quantity adjustments and dynamic effects}

To explore in more detail the mechanism through which trade finance supply shocks affect export growth, we study adjustments in prices and quantities separately. If the identified shocks represent contractions and expansions in the supply of trade finance, that is, if there is trade finance rationing, U.S. export growth will mostly respond through changes in traded quantities. A rationing of trade finance should leave export prices unaffected if destination markets are competitive. ${ }^{49}$ If the shocks mainly captured changes in the cost of trade finance, then they should have a negative effect on observed prices, as importers may pay less to exporters. ${ }^{50}$

To check these conjectures, we construct the average growth in unit prices and the average growth in traded quantities by destination using industry-level export data from the Census Bureau. ${ }^{51}$ Growth rates of unit prices and quantities are calculated at the HS 10 digit level, which are then weighted by the share of an industry in the total value of exports to country $i$ at time $t$ and summed over all industries. ${ }^{52}$ The first two columns of table 13 show the effect of trade finance supply shocks on unit prices for the entire sample period and for the crisis period, respectively; columns (3) and (4) display regression results for quantities. While the effect of trade finance supply shocks on unit prices is close to zero and not significant, there is a positive and significant effect on quantities. This suggests that the adjustment of U.S. exports is mostly due to changes in quantities, lending further support for the mechanism proposed in this paper.

Another interesting question is whether the effect of trade finance supply shocks is longterm or transient. In table 14, lags and leads of the shock variable are included in the regressions. We find that the one-quarter lagged trade finance supply shock also explains export growth. Higher order lags and leads are not significant. The negative coefficient of the one-quarter lagged shock suggests that reductions in export growth from a trade finance supply shock in period $t$ are partly offset by higher export growth in period $t+1$. To better understand this result, we run regressions separately for the crisis sample and the non-crisis

\footnotetext{
${ }^{49}$ If U.S. firms had substantial market power in a large number of products and a trade finance expansion made them supply larger quantities, a weak negative correlation between trade finance supply shocks and export prices could arise.

${ }^{50}$ This could be the case either because exporters and importers bargain over and share rents or because higher financial costs lead to a reduction in import demand, lowering equilibrium prices.

${ }^{51}$ Industry level trade data with information on quantities is available to us from 2006 onward.

${ }^{52}$ We drop observation in the bottom and top 10th percentiles of the quantity and unit price growth rate distribution, respectively.
} 
sample as shown in columns (4) and (5). While the effects of trade finance supply shocks are in large parts transient in normal times, they are highly persistent in crisis times indicated by the much larger coefficient on the contemporaneous shock (0.17) than on the lagged shock (-0.05) in column (4). Reductions in the supply of trade finance by a single bank may mainly lead to a delay in export transactions until firms have found another bank that can provide the service, but they may harm trade in the long term if they occur during times of financial distress.

\subsection{Identification and Robustness}

In this section, we present several robustness checks. In particular, we address the concern that the constructed country-level shocks could be endogenous to changes in export supply or export demand. We also show that the results are robust to lagging banks' market shares by an alternative number of periods when construction the country-level supply shocks. Combined with the previous observation that the estimated bank-level shocks are not positively serially correlated, this rules out endogeneity due to sorting of banks into markets.

Ruling out demand effects If banks were fully specialized along a certain dimension, e.g. in firms or industries, and there was a shock to demand or production of the firm or industry, then the estimated bank shocks could reflect changes in exports. Dropping country $i$ information from the sample would not be sufficient to eliminate this endogeneity. To see this, consider the following example. Assume that there are two banks. Bank A specializes in confirming LCs for machinery, and bank B provides guarantees for exports of textiles. Suppose there is a shock to the supply of or the global demand for machinery so that exports in that industry increase. Then bank A faces a higher demand for trade finance and its trade finance claims increase. Because bank A sees an increase in the demand for LCs but not bank B, the estimation strategy could fail to filter out the demand effect, and the increase in the demand for trade finance could show up as a positive shock to bank A's supply of trade finance. When exports of machinery increase to all destination countries, bank shocks identified without the inclusion of bank A's trade finance claims in country $i$ could still be correlated with exports to country $i$.

To address such concerns, we restrict the set of countries employed when estimating the bank-level supply shocks. First, we only use observations for the large countries in the sample to estimate equation 1 . Thus we obtain bank-time fixed effects that exclusively reflect 
the growth or contraction of trade finance by U.S. banks in the large export destinations, whose imports from the U.S. should be more diversified in terms of firms, industries etc. We use these bank-level shocks to construct country-level supply shocks as before and rerun the regressions on the sample of small and large countries. ${ }^{53}$ Table 15 presents the results. When the export equation is estimated based on the sample of large countries, the effect of letter of credit supply shocks is close to zero and insignificant (columns (1) and (2)). Thus information on trade finance supplied to large countries does not predict U.S. export growth in large destinations. If the bank-level shocks picked up changes in the demand for trade finance, we should see the opposite. The estimated shocks therefore have to either represent trade finance supply shocks or be uninformative but they cannot be driven by demand-side factors. Column (3) shows that the shocks are able to predict export growth in the small destination countries that were excluded in the construction of the supply shocks. The samples of small and large countries do not systematically vary in their ratio of trade finance claims to U.S. exports, so the hypothesis that our results are driven by the demand for trade finance is hard to defend in consideration of this evidence.

While the first robustness check presented above is, in our view, conclusive in regard of the role of demand effects, we do additional exercises that more specifically address concerns about industry and regional specialization. Next, we use the fact that countries differ substantially in the types of goods they import from the U.S. We compute the average share $\bar{s}_{k i}$ of industry $k$ in U.S. exports to country $i$ over the sample period. Then, we compute for each country $i$ and each country $j$ the sum of squared differences in industry shares between the two countries using the following formula: $\sum_{k=1}^{K}\left(\bar{s}_{k i}-\bar{s}_{k j}\right)^{2}$. Next, we rank countries according to how similar they are to country $i$. This information is then used to systematically exclude countries from the sample on which the bank shocks for country $i$ are estimated. Specifically, we always exclude the 30 countries that are closest to country $i$ (in terms of the industry structure of their U.S. imports) when estimating equation 1 for country $i$. The estimated bank-level shocks are aggregated to obtain country-level shocks as before. The results of this exercise are shown in columns (1) to (3) table 16. The effect of letter of credit supply shocks on export growth is still large and highly significant. That is, even when we exclude those countries that are the most similar in terms of the goods they import from the U.S. when we estimate the bank-level shocks, the results still hold.

In a third exercise, we exclude yet another set of countries when estimating equation 1.

\footnotetext{
${ }^{53}$ For a list of countries designated as small, see the data appendix.
} 
Trade patterns are more dissimilar, the more different destination countries are in terms of their geographic location and stages of development. Hence, we drop not only information on country $i$ but also on the entire region in which country $i$ is located to obtain the banklevel shocks $\alpha_{i b t}$ that are used to compute the aggregate supply shock of country $i$. We split countries into eight regions: East Asia and Pacific, Europe and Central Asia, High-income OECD members, High-income non-OECD members, Latin America and the Caribbean, the Middle East and North Africa, South Asia, and Sub-Saharan Africa. The results are qualitatively the same, as columns (4) to (6) of table 16 show.

Evidence against specialization of banks in industries We now provide evidence against the hypothesis that banks specialize in particular firms or industries and that such specialization drives our results. Note that specialization would imply that a bank's share in the total trade finance claims of country $i$ is correlated with the country-level export share of the industry in which the bank specializes. In addition, the estimated bank shocks would be correlated with specific industry shocks. To check for evidence of the former relationship, we regress a particular bank's trade finance shares that vary across countries and over time on the export shares of different industries, which also vary across countries and over time. We split industries into fourteen groups. ${ }^{54}$ The regression equation reads as follows:

$$
\phi_{i t}^{b}=\sigma^{k} \text { industry } \operatorname{share}_{i t}^{k}+\delta_{i}+\psi_{i t}
$$

where $\phi_{i t}^{b}=\frac{t f_{i b t}}{\sum_{b}^{B} t f_{i b t}}$ and industry share $e_{i t}^{k}=\frac{X_{i k t}}{\sum_{k}^{K} X_{i k t}} . X_{i k t}$ stands for the exports in industry $k$ to country $i$ at time $t$. This regression is estimated for each bank $b$ and each industry $k$.

In a next step, we obtain industry shocks $\alpha_{k t}$ by running the following regression:

$$
\Delta X_{k i t}=\alpha_{k t}+\beta_{i t}+\epsilon_{k i t}
$$

where $\Delta X_{k i t}$ reflect the growth in U.S. exports to destination $i$ in industry $k$ at time $t$. As with the bank-level shocks, we regress the estimated industry shocks $\alpha_{k t}$ on time fixed effects and work with the residuals $\hat{\alpha}_{k t}$. Then we regress the average bank shocks $\bar{\alpha}_{b t}$, bank by bank, on the different industry shocks:

$$
\bar{\alpha}_{t}^{b}=\theta^{k} \hat{\alpha}_{t}^{k}+\xi_{t}
$$

\footnotetext{
${ }^{54}$ These are Stone \& Glass; Chemicals \& Allied Industries; Transportation, Raw Hides, Skins, Leather, \& Furs; Miscellaneous; Machinery \& Electrical; Wood \& Wood Products; Footwear \& Headgear; Plastics \& Rubbers; Food; Textiles; Mineral Products; Metals; Other.
} 
Table 17 displays the results for the five largest banks. Each column presents the estimated coefficients for a particular bank. Each row reflects a particular industry. Even columns show the coefficients obtained from estimating equation $5\left(\sigma^{k}\right)$, odd columns those from estimating equation $7\left(\theta^{k}\right)$. The table indicates that the trade finance shares of banks do not co-vary systematically with the export shares of particular industries. Also industry shocks do not explain bank shocks. Note that it is not a concern that some of the coefficients in table 17 are positive and significant. Specialization would imply that $\sigma^{k}$ and $\theta^{k}$ are both positive and significant for a particular bank $b$ and industry $k$ but this is never the case. We also ran regressions for the other banks in our sample and regressed the log of the trade finance claims of a particular bank on the log of exports in different industries. Each bank's trade finance claims are correlated with exports in more than one industry. At the same time, exports of the same industry explain the variation in the trade finance claims of multiple banks. There is no indication that banks specialize and serve only a single industry or large firm and that this could drive the presented results.

Beyond the econometric evidence just provided, there are also some basic observations that make it very unlikely that banks specialize in industries or that exports of single firms could drive changes in the trade finance claims of single banks and aggregate export growth rates at the same time. There are only a few banks that provide trade finance, while there are many more firms and industries. While it is true that international trade is highly concentrated, concentration is much lower than in the trade finance business. Bernard et al. (2009) report that in 2000 the top 1 percent of exporters, or 2245 firms, were responsible for 80.9 percent of all U.S. exports. In contrast, in our data in 2012, 5 banks accounted for more than 90 percent of U.S. banks' trade finance. It is unlikely that idiosyncratic shocks to any of these 2245 firms would matter for the business of any of these very large trade finance suppliers. So the mere fact that the provision of guarantees is concentrated in a few large banks makes specialization improbable. Also, the largest firms are less likely to rely on LCs. Larger firms have longer lasting relationships and are better able to cope with risks, since they are big and can diversify within the firm. ${ }^{55}$ Moreover, a substantial amount of their trade is intra-firm and does not require bank guarantees. Third, banks should seek to spread trade financing over different industries and firms. On one hand, banks want to diversify risks. On the other hand, the costs associated with gathering LC-relevant information about

\footnotetext{
${ }^{55}$ Antràs and Foley (forthcoming) report that the large U.S. food exporter they study employs letters of credit for only 5.5 percent of its exports. This is substantially smaller than the 8.8 percent found by Niepmann and Schmidt-Eisenlohr (2013) for overall U.S. exports. See Monarch and Schmidt-Eisenlohr (2015) for evidence that relationships of larger firms are systematically longer-lasting.
} 
a destination and establishing a network of correspondent banks is likely much higher than the cost of acquiring knowledge about an industry.

Country specialization of banks The reader might also be worried that country-level shocks could have feedback effects on banks because these specialize in certain countries and, as a result, are highly exposed to these economies. Suppose, for example, that a bank had most of its business in Argentina. Then, a downturn in Argentina could lead to large losses for that bank and trigger reductions in its supply of trade finance across all markets. To the extent that the Argentina shock moves the bank's trade finance positions in other countries, we would estimate a negative idiosyncratic shock for that bank, and, through the aggregation of bank-level shocks, could get a negative trade finance supply shock for Argentina. A closer inspection of the data and our results shows that this is not an issue in our application. We find that shocks to the top 5 banks explain export growth in the small destinations. No trade finance position of any of the top 5 banks in the small countries represents more than 2.8 percent of the bank's total trade finance claims (the mean share is 0.2 percent). Even a full default of one of these small export destination would therefore be insufficient to trigger any quantitatively relevant adjustments at these banks.

Sorting The previous discussion addresses concerns that the idiosyncratic bank shocks we obtain could be endogenous to export growth. Any remaining endogeneity between countrylevel shocks and export growth rates must thus come through banks' market shares. The identification assumption would be violated if banks with positive shocks in period $t$ were to provide more trade finance in period $t-2$ to markets with positive deviations from trend export growth in period $t$.

In columns (1), (2) and (3) of table 18, banks' market shares are lagged by one, three and four quarters, respectively, when computing the country shocks $\Delta t f_{c t}$, in contrast to the two-quarter lags used in the baseline specification. In column (4), four-quarter rolling averages of banks' market shares lagged by one period are used. In column (5), the yearly average market share of each bank is applied to construct the country-level shocks in the next year. The effect of supply shocks on export growth remains significant at a 10 percent level throughout. Given these results, our identification strategy could be violated only if banks that anticipate growing in period $t$ sort, in period $t-1, t-2, t-3$ and $t-4$, into markets with higher deviations from trend export growth in period $t$. We have shown in 
section 4.3 that the estimated bank-level shocks are not positively serially correlated. As results hold independent of the number of lags used for the market share variable, systematic sorting of banks period by period can be ruled out.

Placebo test, country time trends and zeros We end the robustness section with a couple of additional checks. In column (1) of table 19, the dependent variable is replaced. Instead of U.S. export growth, we use growth in exports of the EU15 countries to destination $i$ in quarter $t .^{56}$ Accordingly, we do not include growth in non-U.S. exports as control variable in the regression. The estimated shock coefficient is close to zero and insignificant. This indicates, on one hand, that the supply shocks are not correlated with the demand for goods from EU countries. On the other hand, it suggests that there is no substitution of EU goods for U.S. goods in response to U.S. trade finance shocks. In column (2), we include countryspecific linear time trends in the regression in addition to time and country fixed effects. This has essentially no effect on the magnitude and significance of the shock coefficient compared to the baseline result in column (3) of table 10. Thus we can exclude that results are due to an omitted variable that exhibits a time trend and is correlated with both the shocks and export growth. ${ }^{57}$

In column (3), we present a robustness check that addresses concerns related to our sample selection when estimating bank-time fixed effect. Recall that we deleted observations for which $t f_{b c t}$ was equal to zero (see the discussion in section 4.2) when estimating equation 1. To avoid the exclusion of zeros, we compute growth rates using the formula $2 \frac{t f_{b c d}-t f_{b c t-1}}{t f_{b c d}+t f_{b c t-1}}$ suggested by Davis et al. (2007). These alternative growth rates are regressed on banktime fixed effects $\alpha_{b t}$ and country-fixed effects $\beta_{c t}$. The obtained bank-time fixed effects are normalized and used to compute country-level shocks as before. Regressions are run equivalently on export growth rates computed as exp growth gt $_{c t}=2 \frac{\exp _{c t}-\exp _{c t-1}}{\exp p_{c t}+\exp p_{c t-1}}$. Including observation with zero trade finance at $t$ or $t-1$ creates noise in our estimation, but results for the crisis period go through as column (3) shows. The estimated effect of trade finance supply shocks is significant at a 10 percent level and comparable to earlier findings with a beta coefficient of around 10 percent.

\footnotetext{
${ }^{56}$ The EU15 countries include: Austria, Belgium, Denmark, Finland, France, Germany, Greece, Ireland, Italy, Luxembourg, the Netherlands, Portugal, Spain, Sweden, the United Kingdom.

${ }^{57}$ We also checked that results are robust to excluding the period after 2009, in which U.S. banks expanded their trade finance business in particular in Asia.
} 


\section{Quantifying the Effect of Supply Shocks}

In this section, we conduct several experiments to explore the quantitative relevance of trade finance supply shocks for U.S. exports. We will interpret the effect of $\gamma$ as the direct effect of trade finance supply shocks on export growth to country $i$ in the narrative below. However, as discussed in section $4.1, \gamma$ probably represents an upper bound of this direct effect.

We start with the following experiment: we assume that a major trade finance provider experiences a negative supply shock that corresponds to the 10th percentile of the bank shock distribution (a value of -0.426). Using this bank's market share in each destination country in the fourth quarter of 2011 and export values in the first and second quarters of 2012, the predicted aggregate effect on export growth is calculated as follows:

$$
\Delta X_{t}=\frac{\sum_{c=1}^{N}\left(\gamma(-0.426) \phi_{c b t-2} X_{c t-1}\right)}{X_{t-1}}
$$

We set $\gamma$ equal to 0.0888 , which corresponds to the estimated coefficient in column (3) of table 10. The calculations predict that such a trade finance supply shock would reduce aggregate U.S. export growth by 1.4 percentage points.

It does matter which bank is subject to the shock. In a next step, we choose two large trade finance suppliers and calculate the effect on export growth in selected regions of the world when each of them is hit by the shock described above. Columns (1) and (2) of table 20 show the results. Whereas exports in South Asia would fall by 0.41 percentage point if bank A were hit by the shock (see column (1)), the same relative reduction in trade finance by bank B would reduce exports in this region by 1.86 percentage points (see column (2)). An even stronger asymmetry arises for Sub-Saharan Africa. This example illustrates that banks, through their global operations, can influence export patterns. The same bank shock affects countries differentially, depending on how important the bank is for the provision of LCs in each export market.

So far, we focused on what happens when only one of the banks reduces its supply of

trade finance. Next, we analyze the effect on exports if all banks were hit by a moderate shock that corresponds to the 25th percentile of the bank-level shock distribution (a value of $\left.\alpha_{b t}=-0.245\right)$ and roughly to half of the shock considered before. Using the estimated loan growth coefficient in column (4) of table 10, aggregate U.S. exports would fall by around 2.2 percentage points. According to the results presented in section 5, the effect of letter of 
credit supply shocks is larger during a crisis period. Based on the coefficient in column (3) of table 11, the effect would double to 4.4 percentage points. ${ }^{58}$

There is also evidence that the effect of shocks varies across countries. Smaller export markets are more affected than larger markets by a reduction in the supply of trade finance. To account for this, we calculate the effect of supply shocks now based on the estimated relationship in column (8) of table 11 for different regions of the world during crisis times. Compared to other regions, sub-saharan Africa would be hit particularly hard by a reduction in the supply of letters of credit as (4) of table 20 shows, since this region hosts many small export markets.

As a final exercise, we compare the effect of an LC supply shock to the effect of an exchange rate shock. According to the estimated coefficient in column (3) of table 11, a 10percent appreciation of the USD against the local currency of the importing country reduces U.S. exports by 2.53 percentage points. Hence, the effect of a negative LC supply shock of one standard deviation during a crisis episode generates the same reduction in trade as an appreciation of the USD by 12.3 percent. The effects of trade finance supply shocks are comparable to those of exchange rate changes. ${ }^{59}$

The preceding exercises illustrate that trade finance supply shocks are economically relevant for exports. This is particularly true for exports to small countries during times of financial stress, with a beta coefficient of 0.17 . The overall role of trade finance for exports is likely larger. Recall that our estimation strategy only identifies effects of trade finance supply shocks through the risk channel. Shocks to the supply of letters of credit should affect trade flows over and above the effects of shocks to the supply of credit identified by Paravisini et al. (2015).

Note further that $\gamma$ is the elasticity of export growth to bank-specific trade finance supply changes. To disentangle the supply of from the demand for trade finance, the estimated bank-level shocks are purged of any aggregate effects. While necessary for identification, it also means that aggregate trade finance supply shocks, for example during the Great Trade Collapse, cannot be quantified and their effects cannot be estimated. This limitation is not specific to our paper but is a general feature of any cross-sectional estimation strategy like the ones employed by Amiti and Weinstein (2011) and Paravisini et al. (2015).

\footnotetext{
${ }^{58}$ Relative to non-crisis times the effect more than doubles.

${ }^{59}$ We estimate the contemporaneous exchange rate elasticity of U.S. exports. Estimates of the long-run elasticity are typically higher. See, for example Hooper et al. (2000). The beta coefficient of the exchange rate is 5.2 percent, comparable to the beta coefficient of trade finance supply shocks, which is 5 percent.
} 
We have seen that reductions in the supply of trade finance by single banks have larger effects during times of financial distress. This is probably because exporters find it harder to switch to other banks, which may be less willing to expand their balance sheets or to cooperate with new banks in foreign countries when uncertainty is high and liquidity limited. Switching might be even harder in the presence of an aggregate reduction in the supply of trade finance, which, according to industry reports, happened in 2008. We therefore conclude that trade finance, through the risk channel, very likely played a magnifying role in the Great Trade Collapse, with larger effects for exports to the smaller and poorer countries.

\section{Conclusions}

Exploiting data on the trade finance claims of U.S. banks that vary across countries and over time, this paper sheds new light on the effects of financial shocks on trade. While existing studies emphasize the working capital channel, this work provides evidence for the risk channel. We show that shocks to the supply of LCs - a trade-specific, risk-reducing financial instrument - have statistically and economically significant effects on exports.

While we follow the strategy of Greenstone et al. (2014) and Amiti and Weinstein (2013) to identify supply shocks from the data, we modify and add new elements to the methodology. First, we estimate bank shocks over multiple periods and propose a normalization to make bank shocks comparable across time. Second, we obtain bank shocks separately for each country and show how to systematically drop information on similar countries to counter endogeneity concerns that may arise. Third, we demonstrate how sorting into markets can be excluded by jointly looking at serial correlation in bank shocks and by estimating the model using different lags of the market shares. These innovations can be useful for future empirical work.

Applying the approach, we find that exports to countries that are poorer and smaller, where fewer U.S. banks are active, are more affected when banks reduce their supply of trade finance. At the same time, changes in supply have much stronger effects during times of financial distress. Another key result of the analysis is that single banks can affect exports in the aggregate. Due to the high concentration of the business, a large negative shock to one of the big U.S. trade finance banks reduces aggregate exports by 1.4 percentage points. This effect more than doubles during times of financial distress. The presented findings suggest that trade finance can constrain exports, especially to the poorer and smaller destinations 
and during crises episodes. Considering that reductions in the supply of LCs are associated with a contraction in bank lending and a rise in banks' credit default swap spreads, trade finance may have a role in explaining the collapse in exports to the smaller and poorer countries in 2008/2009. 


\section{References}

Ahn, JaeBin, "Estimating the Direct Impact of Bank Liquidity Shocks on the Real Economy: Evidence from Letter-of-Credit Import Transactions in Colombia," 2013. mimeo.

Amiti, Mary and David E. Weinstein, "Exports and Financial Shocks," The Quarterly Journal of Economics, 2011, 126 (4), 1841-1877.

_ and _ , "How Much do Bank Shocks Affect Investment? Evidence from Matched BankFirm Loan Data," Working Paper 18890, National Bureau of Economic Research March 2013.

Antràs, Pol and C. Fritz Foley, "Poultry in Motion: A Study of International Trade Finance Practices," Journal of Political Economy, forthcoming.

Ashcraft, Adam B., "Are Banks Really Special? New Evidence from the FDIC-Induced Failure of Healthy Banks," The American Economic Review, 2005, 95 (5), 1712-1730.

Asmundson, Irena, Thomas William Dorsey, Armine Khachatryan, Ioana Niculcea, and Mika Saito, "Trade and trade finance in the 2008-09 financial crisis," IMF Working Papers 11/16 2011.

Auboin, Marc and Martina Engemann, "Testing the trade credit and trade link: evidence from data on export credit insurance," Review of World Economics, 2014, pp. 1-29.

Beck, Thorsten, "Financial Dependence and International Trade," Review of International Economics, May 2003, 11 (2), 296-316.

Bernanke, Ben S, "Nonmonetary Effects of the Financial Crisis in the Propagation of the Great Depression," The American Economic Review, 1983, 73 (3), 257-276.

Bernard, Andrew B, J Bradford Jensen, and Peter K Schott, "Importers, exporters and multinationals: a portrait of firms in the US that trade goods," in "Producer dynamics: New evidence from micro data," University of Chicago Press, 2009, pp. 513-552.

Bruno, Valentina and Hyun Song Shin, "Cross-border banking and global liquidity," Review of Economic Studies, April 2015, 82 (2), 535-564.

Cetorelli, Nicola and Linda S. Goldberg, "Banking Globalization and Monetary Transmission," The Journal of Finance, 2012, 67 (5), 1811-1843. 
Chodorow-Reich, Gabriel, "The Employment Effects of Credit Market Disruptions: Firm-level Evidence from the 2008-09 Financial Crisis," The Quarterly Journal of Economics, 2014, 129 (1), 1-59.

Chor, Davin and Kalina Manova, "Off the cliff and back? Credit conditions and international trade during the global financial crisis," Journal of International Economics, $2012,87(1), 117-133$.

Davis, Steven J, John Haltiwanger, Ron Jarmin, and Javier Miranda, "Volatility and dispersion in business growth rates: Publicly traded versus privately held firms," in “NBER Macroeconomics Annual 2006, Volume 21,” MIT Press, 2007, pp. 107-180.

Del Prete, Silvia and Stefano Federico, "Trade and finance: is there more than just trade finance? Evidence from matched bank-firm data," Economic working papers 948, Bank of Italy January 2014.

G20, "London Summit Leaders' Statement," Technical Report April 2009.

Greenstone, Michael, Alexandre Mas, and Hoai-Luu Nguyen, "Do credit market shocks affect the real economy? Quasi-experimental evidence from the Great Recession and 'normal' economic times," Working Paper 20704, National Bureau of Economic Research 2014.

Hale, Galina, Christopher Candelaria, Julian Caballero, and Sergey Borisov, "Bank Linkages and International Trade," Working Paper 2013-14, Federal Reserve Bank of San Francisco June 2013.

Head, Keith, Thierry Mayer, and John Ries, "The erosion of colonial trade linkages after independence," Journal of International Economics, May 2010, 81 (1), 1-14.

Hoefele, Andreas, Tim Schmidt-Eisenlohr, and Zhihong Yu, "Payment Choice in International Trade: Theory and Evidence from Cross-country Firm Level Data," CESifo Working Paper Series 4350, CESifo Group Munich 2013.

Hooper, Peter, Karen Johnson, and Jaime Marquez, "Trade Elasticities for G-7 Countries," Princeton Studies in International Economics, August 2000, $8 \%$.

ICC, "Global Risks - Trade Finance Report 2013," Technical Report, International Chamber of Commerce April 2013. 
IFC, "Global Trade Finance Program Brochure," Technical Report, International Finance Corporation January 2012.

Kalemli-Ozcan, Sebnem, Elias Papaioannou, and Fabrizio Perri, "Global Banks and Crisis Transmission," Journal of International Economics, 2013, 89 (2), 495-510.

Khwaja, Asim Ijaz and Atif Rehman Mian, "Tracing the Impact of Bank Liquidity Shocks: Evidence from an Emerging Market," American Economic Review, 2008, 98 (4), $1413-42$.

Kletzer, Kenneth and Pranab Bardhan, "Credit markets and patterns of international trade," Journal of Development Economics, 1987, 27 (1), 57-70.

Manova, Kalina, "Credit constraints, heterogeneous firms, and international trade," The Review of Economic Studies, 2013, 80 (2), 711-744.

Mian, Atif and Amir Sufi, "Household Leverage and the Recession of 2007-09," IMF Economic Review, 2010, 58 (1), 74-117.

Monarch, Ryan and Tim Schmidt-Eisenlohr, "Learning and the Value of Relationships in International Trade," 2015. Federal Reserve Board, mimeo.

Niepmann, Friederike and Tim Schmidt-Eisenlohr, "International Trade, Risk, and the Role of Banks," Staff Reports 633, Federal Reserve Bank of New York September 2013.

Ongena, Steven, Jose Luis Peydro, and Neeltje van Horen, "Shocks Abroad, Pain at Home? Bank-Firm Level Evidence on the International Transmission of Financial Shocks," DNB Working Papers 385, Netherlands Central Bank July 2013.

Paravisini, Daniel, Veronica Rappoport, Philipp Schnabl, and Daniel Wolfenzon, "Dissecting the effect of credit supply on trade: Evidence from matched credit-export data," The Review of Economic Studies, 2015, 82 (1), 333-359.

Peek, Joe and Eric S. Rosengren, "The International Transmission of Financial Shocks: The Case of Japan," American Economic Review, September 1997, 87 (4), 495-505.

_ and _ , "Collateral Damage: Effects of the Japanese Bank Crisis on Real Activity in the United States," American Economic Review, March 2000, 90 (1), 30-45. 
Schmidt-Eisenlohr, Tim, "Towards a theory of trade finance," Journal of International Economics, 2013, 91 (1), 96 - 112.

Van der Veer, Koen, "The Private Credit Insurance Effect on Trade," Journal of Risk and Insurance, forthcoming.

Working Group on Trade, Debt and Finance, "Improving the availability of trade finance in developing countries: an assessment of remaining gaps," Note by the Secretariat, World Trade Organization 2014. 


\section{Data Appendix}

\section{Data sources}

- U.S. banks' trade finance claims: FFIEC009 Report, Statistics Group, New York Fed.

- SWIFT MT700 messages received by U.S. banks: the SWIFT Institute.

- Quarterly trade data: IMF Direction of Trade Statistics.

- Quarterly industry-level trade data: Census Bureau.

- Bank balance sheet data: FFIEC031 or Y9c reports. Where available, FFIEC031 information was aggregated up for each Bank Holding Company to match the FFIEC009 reporting level.

- Quarterly GDP was obtained from national statistical agencies via Haver Analytics' Data Link Express (DLX) Software.

- Annual population, GDP per capita: World Development Indicators, the World Bank.

- Rule of law: World Government Indicators, the World Bank.

- Distance: CEPII (see Head et al. (2010)).

- Exchange rates: International Financial Statistics, IMF.

- Quarterly credit default swap spreads on senior unsecured debt with maturity 6 months in USD: Markit.com. Matching between ticker names and IDRSSDs was done manually. Quarterly data was obtained by averaging the monthly data.

\section{List of countries}

- Countries designated as offshore financial centers: Netherlands Antilles, Antigua and Barbados, Azerbaijan, Bahrain, Bahamas, Belize, Bermuda, Barbados, Cayman Islands, Cyprus, Dominica, Grenada, Hong Kong, Ireland, Jordan, Lebanon, Macao, Monaco, Maldives, Malta, Mauritius, Seychelles, Vanuatu, Samoa.

- Countries designated as small export destinations: Afghanistan, Algeria, Angola, Armenia, Azerbaijan, Bahrain, Bangladesh, Barbados, Belarus, Belize, Benin, Bermuda, 
Bolivia, Botswana, Brunei Darussalam, Bulgaria, Burkina Faso, Cabo Verde, Cambodia, Cameroon, Democratic Republic of Congo, Republic of the Congo, Cote d'Ivoire, Croatia, Cyprus, Czech Republic, Denmark, Djibouti, Estonia, Ethiopia, Fiji, French Polynesia, Gabon, Georgia, Ghana, Greece, Guinea, Guyana, Haiti, Hungary, Iceland, Iraq, Jordan, Kazakhstan, Kenya, Latvia, Lebanon, Liberia, Libya, Lithuania, Luxembourg, Macau, Macedonia, Madagascar, Malawi, Maldives, Mali, Malta, Mauritania, Mauritius, Mongolia, Morocco, Mozambique, Namibia, Nepal, Netherlands Antilles, New Caledonia, Nicaragua, Oman, Pakistan, Papua New Guinea, Paraguay, Portugal, Qatar, Romania, Rwanda, Samoa, Senegal, Slovakia, Slovenia, Sri Lanka, Sudan, Suriname, Swaziland, Syria, Tanzania, Togo, Trinidad \& Tobago, Tunisia, Turkmenistan, Uganda, Ukraine, Uruguay, Uzbekistan, Yemen, Zambia, Zimbabwe. 
Figure 1: How a letter of credit works

Contract

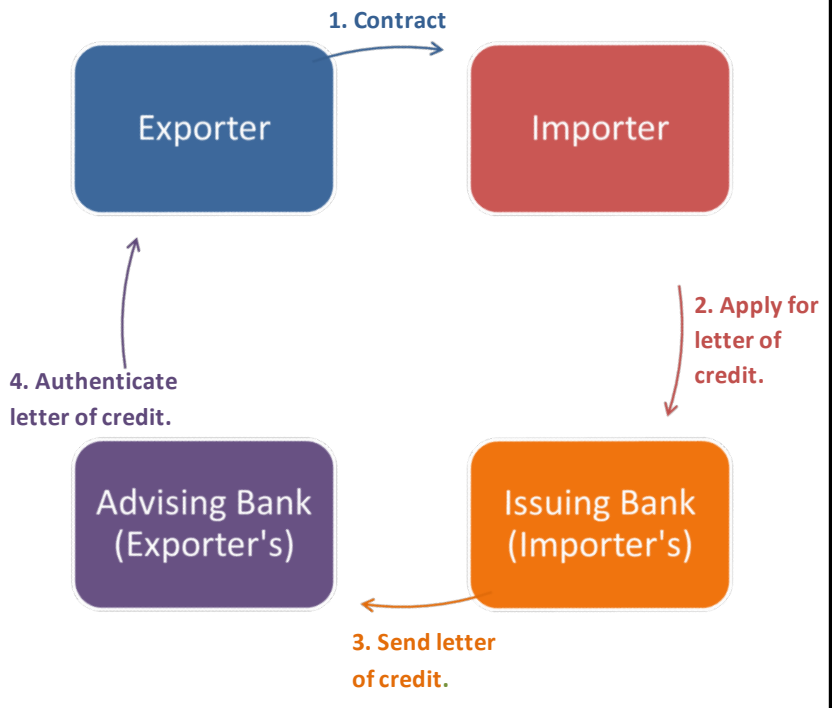

\section{Execution}

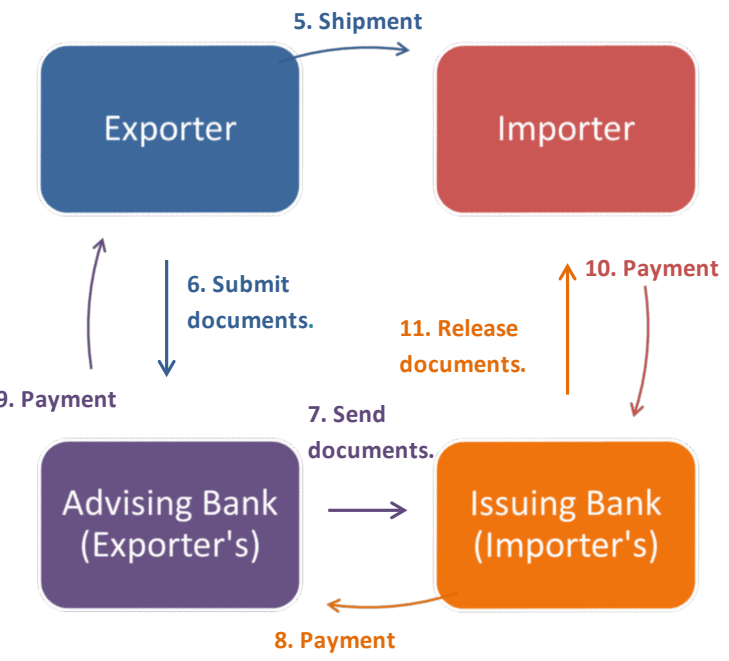


Figure 2: Evolution of aggregate trade finance claims and U.S. exports over time

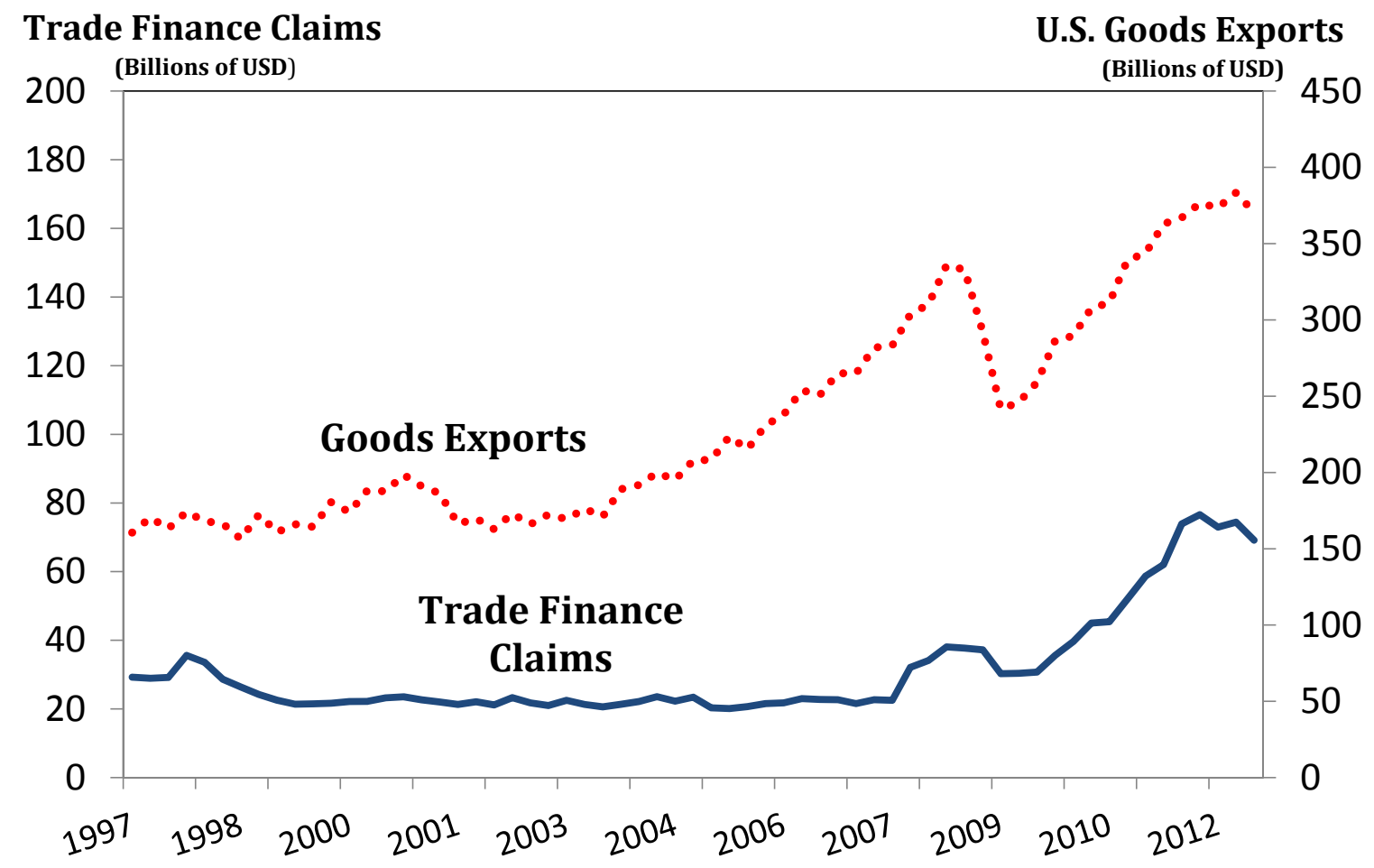

Note: The solid line in the graph shows the aggregate trade finance claims of all reporting U.S. banks over time. The years 1997-2000 exclude data from one large bank that changed its trade finance business fundamentally in the reporting period. The dotted line displays the evolution of aggregate U.S. exports in goods over time. 
Figure 3: Trade finance and export shares in 2012 q2 by world region

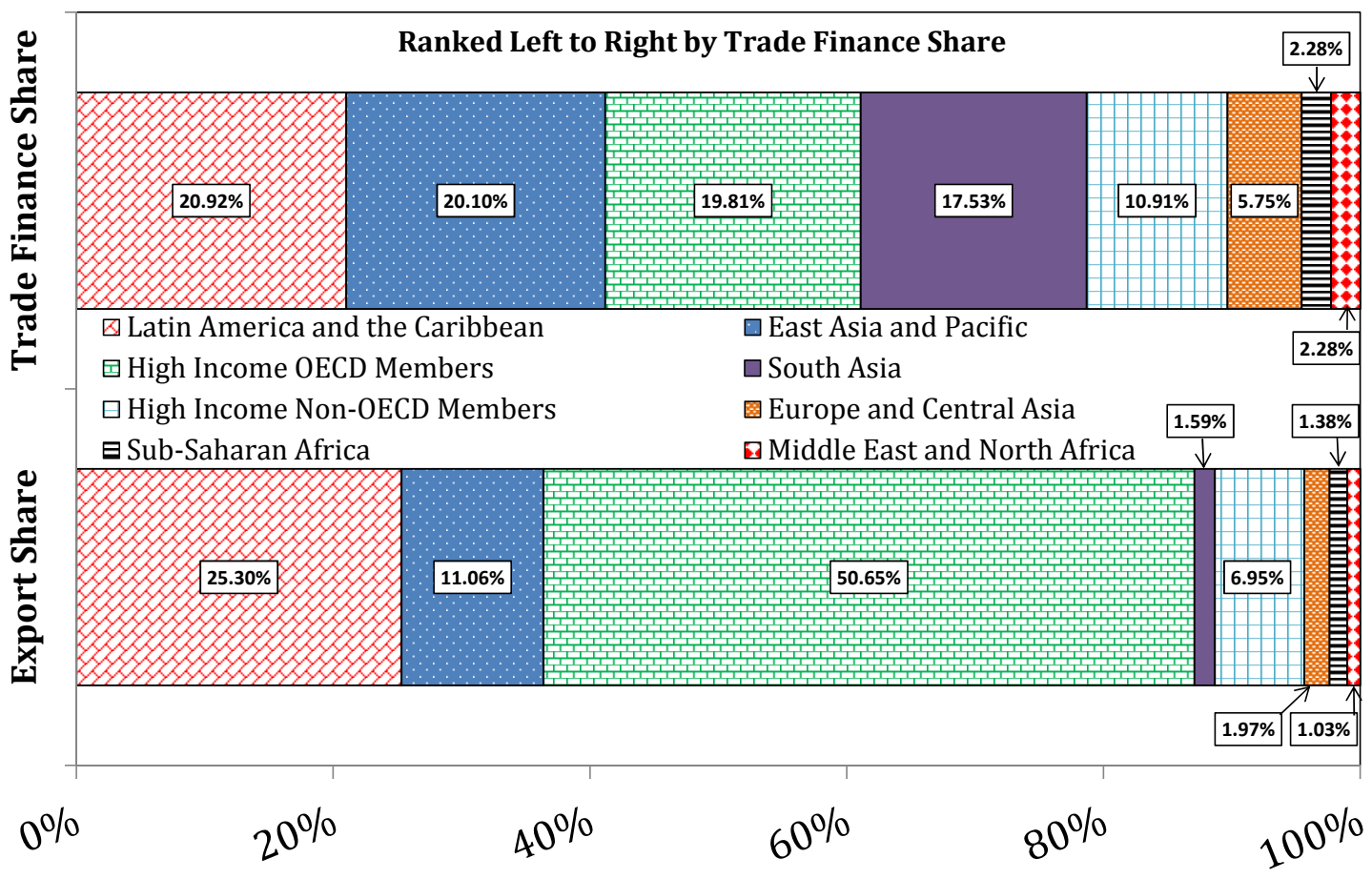

Note: The upper bar in the graph shows the shares of eight groups of countries in banks' total trade finance claims in 2012 q2. The lower graphs displays each group's share in total U.S. goods exports in that quarter. 
Figure 4: Distribution of bank supply shocks

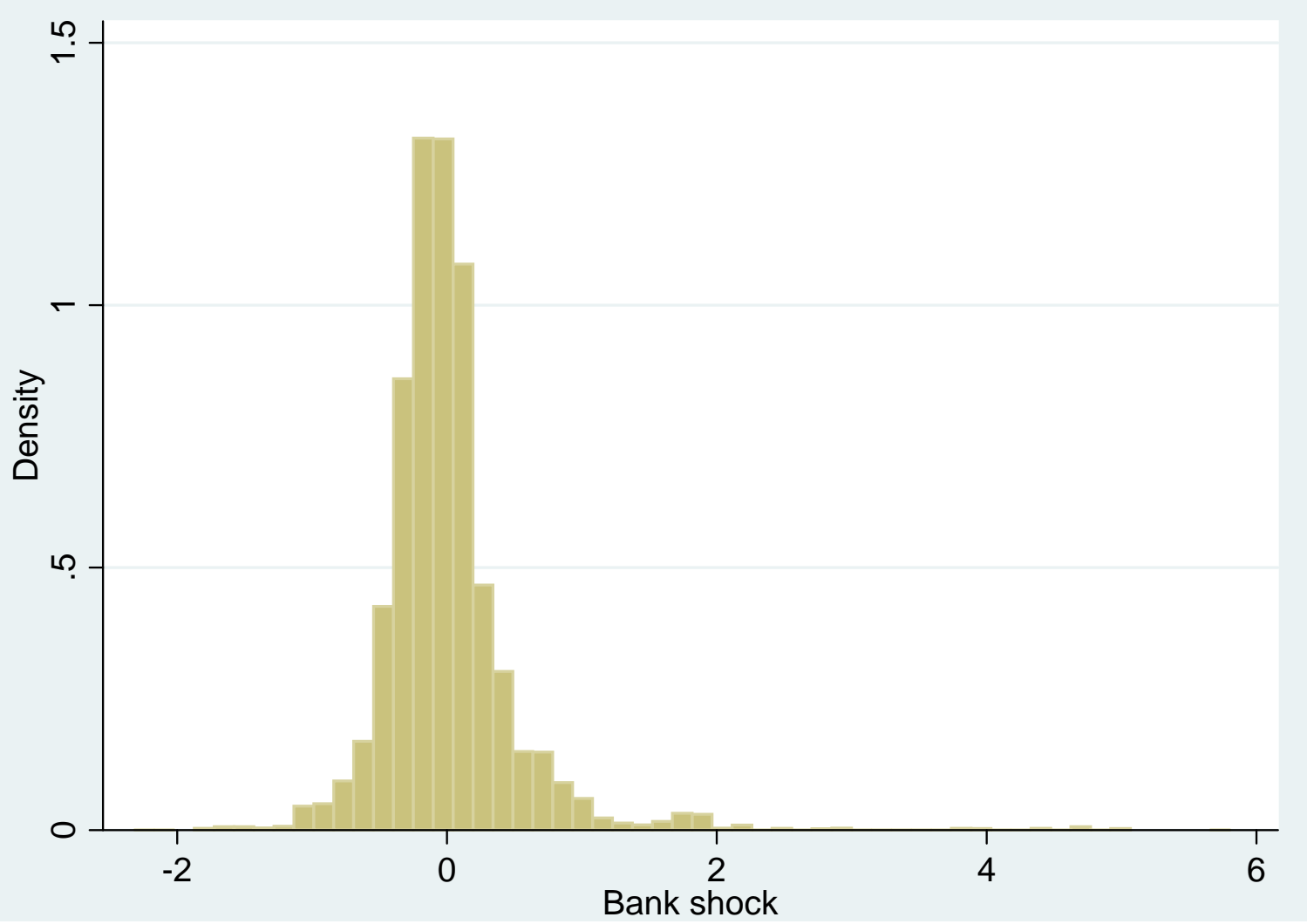

Note: The graph shows the histogram of the 325,389 bank-level shocks that are estimated based on the trade finance data. 
Figure 5: Mean, median and standard deviation of bank supply shocks over time

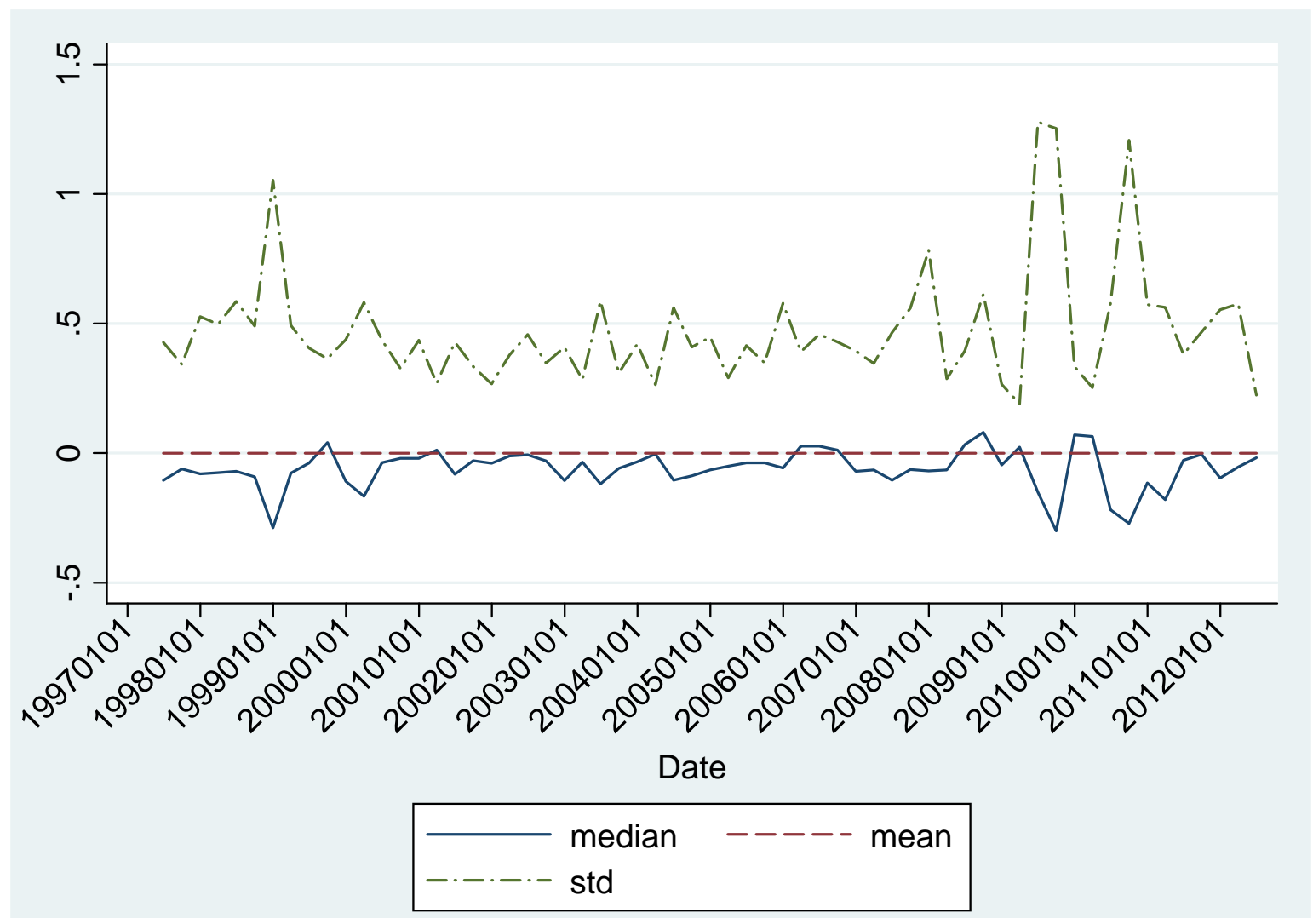

Note: The solid line in the graph shows the median bank-level supply shock over time. The dashed line displays the mean shock. The dash-dotted line reflects the standard deviation of the bank shocks in each quarter. 
Figure 6: Evidence for random distribution of shocks across countries

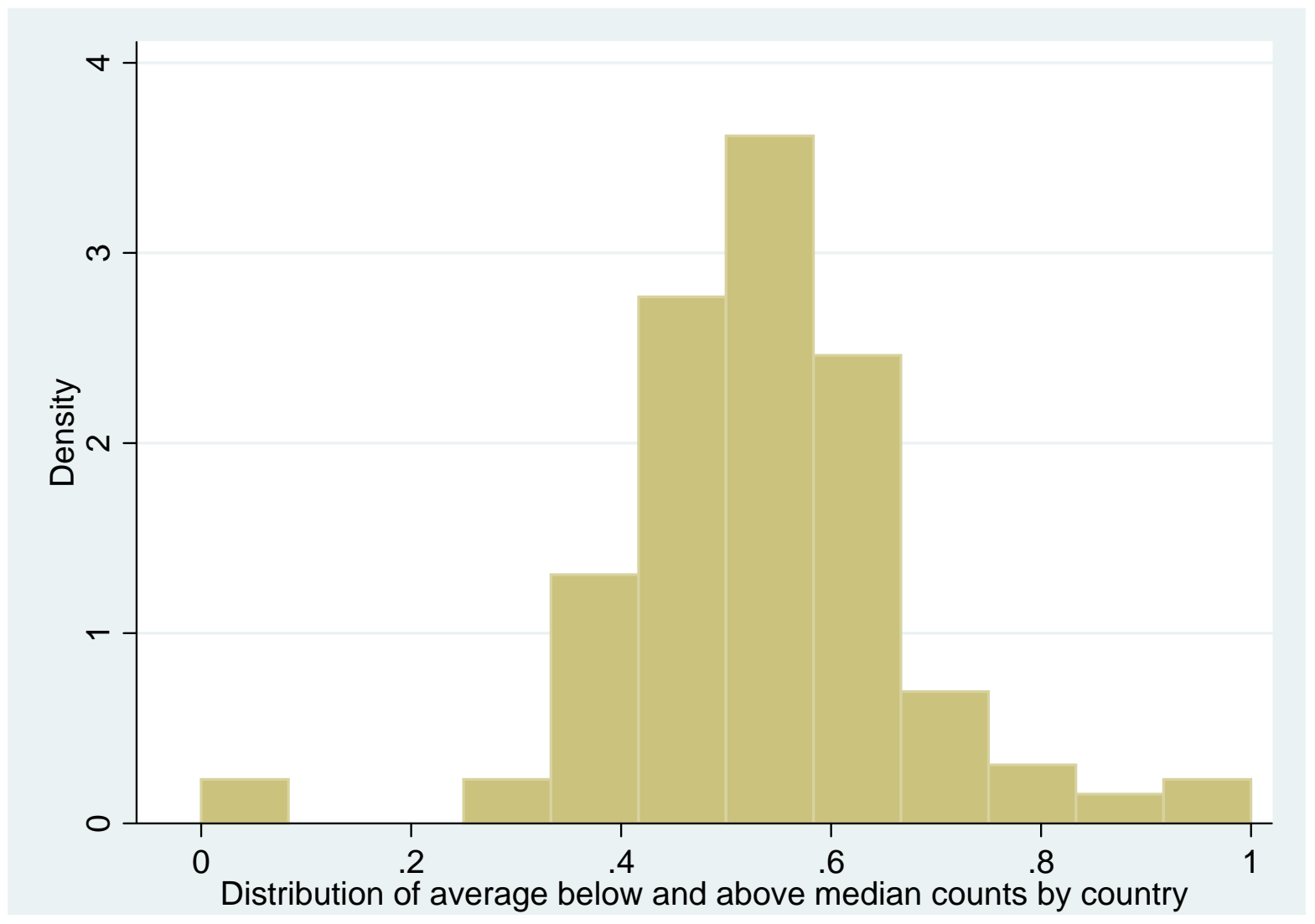

Note: The histogram shows the distribution of country means of a dummy variable that takes value 1 if country $i$ is hit by an above median shock in period $t$ and zero otherwise. If shocks are randomly distributed across countries, then the means should be distributed symmetrically around 0.5 . 
Table 1: Possible instruments and underlying trade transactions in the data

\begin{tabular}{lccc}
\hline \hline & U.S. exports & U.S. imports & Third party trade \\
\hline Pre-export financing (parent) & - & $\mathrm{X}$ & $\mathrm{X}$ \\
Pre-import financing (affiliate) & $\mathrm{X}$ & - & $\mathrm{X}$ \\
LC issuance (affiliate) & $\mathrm{X}$ & - & $\mathrm{X}$ \\
LC confirmation (parent) & $\mathrm{X}$ & - & $\mathrm{X}$ \\
\hline \hline
\end{tabular}

Note: $X$ indicates that this type of trade transaction could be included in the FFIEC 009 data based on the reporting instructions. 


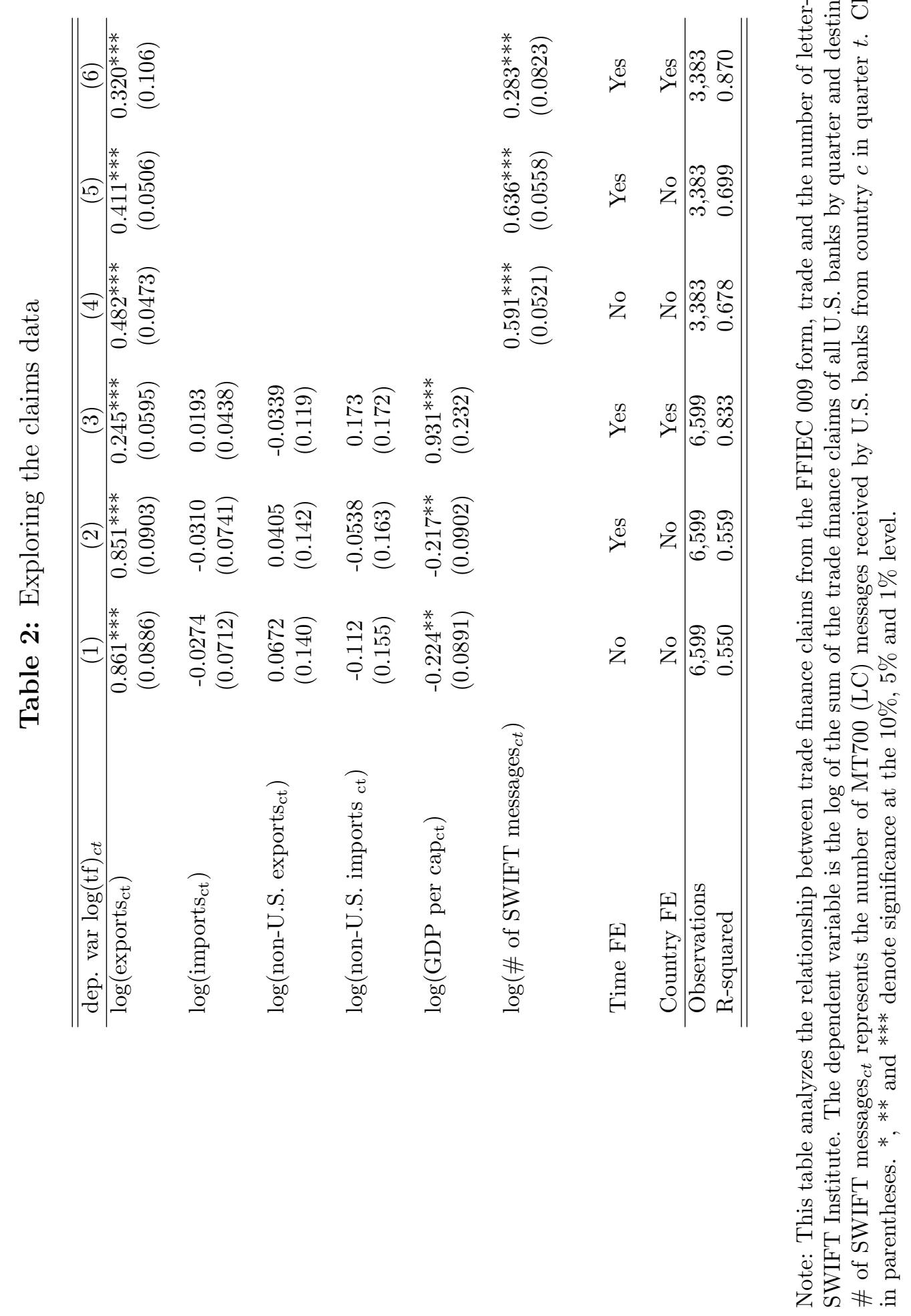


Table 3: Summary statistics of banks' market shares and the number of banks by country

\begin{tabular}{|c|c|c|c|c|c|c|}
\hline & date & $\mathrm{N}$ & mean & std. & $\min$ & $\max$ \\
\hline \multirow[t]{3}{*}{$\phi_{i b t}$} & $2000 \mathrm{q} 1$ & 758 & 0.151 & 0.250 & 0.0003 & 1 \\
\hline & 2006 q1 & 453 & 0.256 & 0.314 & 0.0003 & 1 \\
\hline & 2012 q1 & 484 & 0.277 & 0.324 & 0.0001 & 1 \\
\hline \multirow[t]{3}{*}{$\mathrm{n}_{i t}$} & $2000 \mathrm{q} 1$ & 115 & 6.591 & 6.569 & 1 & 34 \\
\hline & 2006 q1 & 116 & 3.905 & 2.871 & 1 & 14 \\
\hline & 2012 q1 & 134 & 3.612 & 2.810 & 1 & 13 \\
\hline
\end{tabular}

Note: This table reports summary statistics based on data from the Country Exposure Report (FFIEC 009). $\phi_{i b t}$ is the share of the trade finance claims of bank $b$ in the total trade finance claims of country $i$ at time $t$. $n_{i t}$ is the number of banks with positive trade finance claims in country $i$ at time $t$.

Table 4: Persistence in banks' market shares

\begin{tabular}{lccc}
\hline \hline dep. var. $\phi_{i b t}$ & $(1)$ & $(2)$ & $(3)$ \\
\hline$\phi_{i b t-1}$ & $0.913^{* * *}$ & & \\
& $(0.00331)$ & & \\
$\phi_{i b t-2}$ & & $0.880^{* * *}$ & $0.831^{* * *}$ \\
& & $(0.00399)$ & $(0.00493)$ \\
\hline Observations & 32,896 & 29,538 & 29,538 \\
R-squared & 0.836 & 0.773 & 0.780 \\
\hline \hline
\end{tabular}

Note: This table analyzes the persistence of banks' market shares within countries. The dependent variable is the share of the trade finance claims of bank $b$ in the trade finance claims of all banks in country $i$ at time $t$. All regressions include a constant. The regression in column (3) includes bank fixed effects. Robust standard errors are in parentheses. ${ }^{*},{ }^{*}$ and ${ }^{* * *}$ denote significance at the $10 \%, 5 \%$ and $1 \%$ level.

Table 5: Persistence in the number of banks active in a market

\begin{tabular}{lccc}
\hline \hline dep. var. $\mathrm{n}_{i t}$ & $(1)$ & $(2)$ & $(3)$ \\
\hline $\mathrm{n}_{i t-1}$ & $0.956^{* * *}$ & & $0.690^{* * *}$ \\
& $(0.00440)$ & & $(0.0173)$ \\
& & & \\
$\mathrm{n}_{i t-2}$ & & $0.925^{* * *}$ & $0.265^{* * *}$ \\
& & $(0.00547)$ & $(0.0173)$ \\
\hline Observations & 6,914 & 6,697 & 6,587 \\
R-squared & 0.947 & 0.924 & 0.950 \\
\hline \hline
\end{tabular}

Note: This table analyzes the persistence of the number of banks active in a trade finance market. The dependent variable is the number of banks with positive trade finance claims in country $i$ at time $t$. All regressions include a constant. Robust standard errors are in parentheses. ${ }^{*},{ }^{* *}$ and ${ }^{* * *}$ denote significance at the $10 \%, 5 \%$ and $1 \%$ level. 
Table 6: Summary statistics

\begin{tabular}{lccccc}
\hline \hline & $(1)$ & $(2)$ & $(3)$ & $(4)$ & $(5)$ \\
variable & $\mathrm{N}$ & mean & sd & min & $\max$ \\
\hline trade finance growth $\Delta t f_{b c t}$ & 32,256 & 0.225 & 1.049 & -.904 & 9.8 \\
& & & & & \\
bank shock $\hat{\alpha}_{i b t}$ & 325,389 & 0 & 0.500 & -2.316 & 5.806 \\
country-level shock & & & & & \\
& 6,751 & 0.030 & 0.171 & -0.97 & 2.202 \\
country-level shock & & & & & \\
& & & & \\
export growth $\Delta X_{i t}$ in sample with controls & 4,904 & 0.032 & 0.174 & -0.971 & 1.813 \\
\hline \hline
\end{tabular}

Note: In the first row, summary statistics of trade finance growth rates are given that are observed in the sample that is used to estimate equation 1 . The second row provides summary statistics of the normalized bank shocks that are obtained from estimating equation 1, always dropping country $i$ from the sample. The summary statistics of the country-level shocks in the third row are for all country-level shocks that are computed. In the fourth column only those country-level shocks are included that are used in the estimation of equation 3 with controls. The last row displays summary statistics of the corresponding export growth rates.

Table 7: Predicting observed trade finance growth rates using bank-level shocks

\begin{tabular}{lccc}
\hline \hline dep. var $\Delta t f_{i b t}$ & $(1)$ & $(2)$ & $(3)$ \\
\hline$\hat{\alpha}_{i b t}$ & $0.305^{* * *}$ & $0.307^{* * *}$ & $0.326^{* * *}$ \\
& $(0.0521)$ & $(0.0531)$ & $(0.0680)$ \\
Country FE & no & yes & no \\
Time FE & no & yes & no \\
Time×County FE & no & no & yes \\
& & & \\
\hline Observations & 32,025 & 32,025 & 32,025 \\
R-squared & 0.002 & 0.009 & 0.142 \\
\hline \hline
\end{tabular}

Note: This table analyzes the relationship between the country-specific bank-level shock $\hat{\alpha}_{i b t}$ and the observed growth $\Delta t f_{b i t}$ in bank $b$ 's trade finance claims in country $i$ at time $t$. All regressions include a constant. Standard errors are clustered at the bank-time level and are in parentheses. ${ }^{*},{ }^{* *}$ and ${ }^{* * *}$ denote significance at the $10 \%, 5 \%$ and $1 \%$ level. 
Table 8: Testing whether bank-level supply shocks are serially correlated

\begin{tabular}{lccc}
\hline \hline dep. var $\bar{\alpha}_{b t}$ & $(1)$ & $(2)$ & $(3)$ \\
\hline $\bar{\alpha}_{b t-1}$ & $-0.0883^{* * *}$ & $-0.0909^{* *}$ & $-0.0889^{* *}$ \\
& $(0.0337)$ & $(0.0363)$ & $(0.0420)$ \\
$\bar{\alpha}_{b t-2}$ & & 0.0184 & -0.00572 \\
& & $(0.0292)$ & $(0.0294)$ \\
$\bar{\alpha}_{b t-3}$ & & & -0.0143 \\
& & & $(0.0276)$ \\
$\bar{\alpha}_{b t-4}$ & & & -0.0214 \\
& & & $(0.0298)$ \\
Observations & 1,894 & 1,758 & 1,545 \\
R-squared & 0.012 & 0.015 & 0.017 \\
\hline \hline
\end{tabular}

Note: This table tests for serial correlation in the average bank level supply shocks $\bar{\alpha}_{b t}$, which corresponds to the value of $\hat{\alpha}_{i b t}$ averaged over all countries. All regressions include a constant and time fixed effects. Robust standard errors are in parentheses. ${ }^{*},{ }^{* *}$ and ${ }^{* * *}$ denote significance at the $10 \%, 5 \%$ and $1 \%$ level.

Table 9: Correlation of estimated bank shocks with bank-level variables

\begin{tabular}{|c|c|c|c|c|}
\hline \multirow[t]{2}{*}{ dep. var $\bar{\alpha}_{b t}$} & (1) & $(2)$ & $(3)$ & (4) \\
\hline & all & after 2006 & all & after 2006 \\
\hline \multirow[t]{2}{*}{ loan growth } & $0.333^{*}$ & $0.829 * * *$ & & \\
\hline & $(0.184)$ & $(0.278)$ & & \\
\hline \multirow[t]{2}{*}{ deposit growth $b t$} & 0.0196 & -0.271 & & \\
\hline & $(0.196)$ & $(0.308)$ & & \\
\hline CDS spread $b t$ & & & $\begin{array}{c}-0.0838^{* *} \\
(0.0351)\end{array}$ & $\begin{array}{c}-0.0862^{* * *} \\
(0.0212)\end{array}$ \\
\hline Observations & 2,179 & 469 & 256 & 150 \\
\hline R-squared & 0.073 & 0.069 & 0.343 & 0.432 \\
\hline
\end{tabular}

Note: This table analyzes the relationship between the estimated bank shocks and bank-level variables. The dependent variable is the mean bank shock $\bar{\alpha}_{b t}$, which corresponds to the value of $\hat{\alpha}_{i b t}$ averaged over all countries. CDS spread is the bank-specific current default swap spread of bank $b$ at time $t$. All regressions include bank and time fixed effects. Standard errors clustered by bank and are in parentheses. *, ${ }^{* *}$ and *** denote significance at the $10 \%, 5 \%$ and $1 \%$ level. 


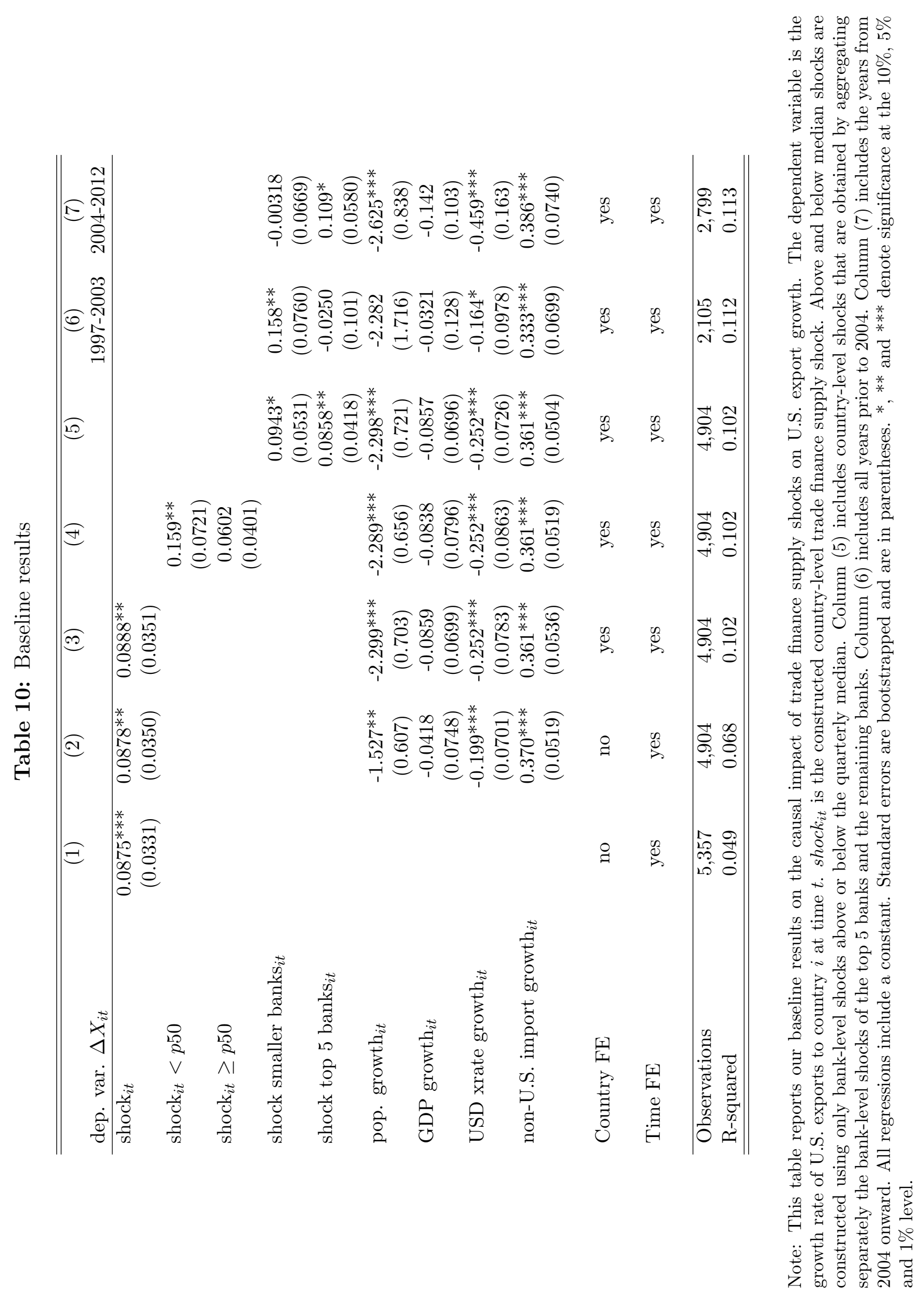




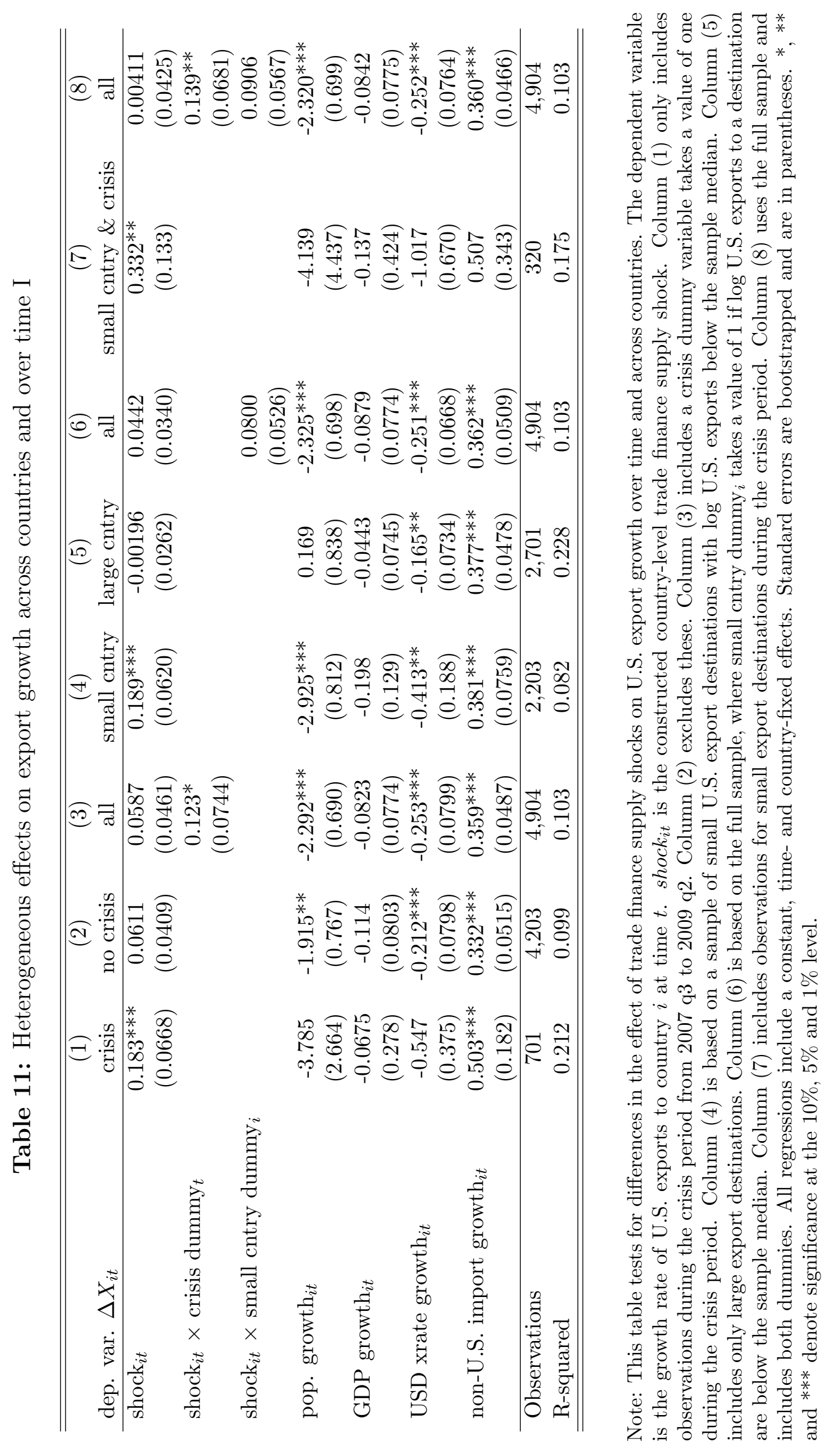




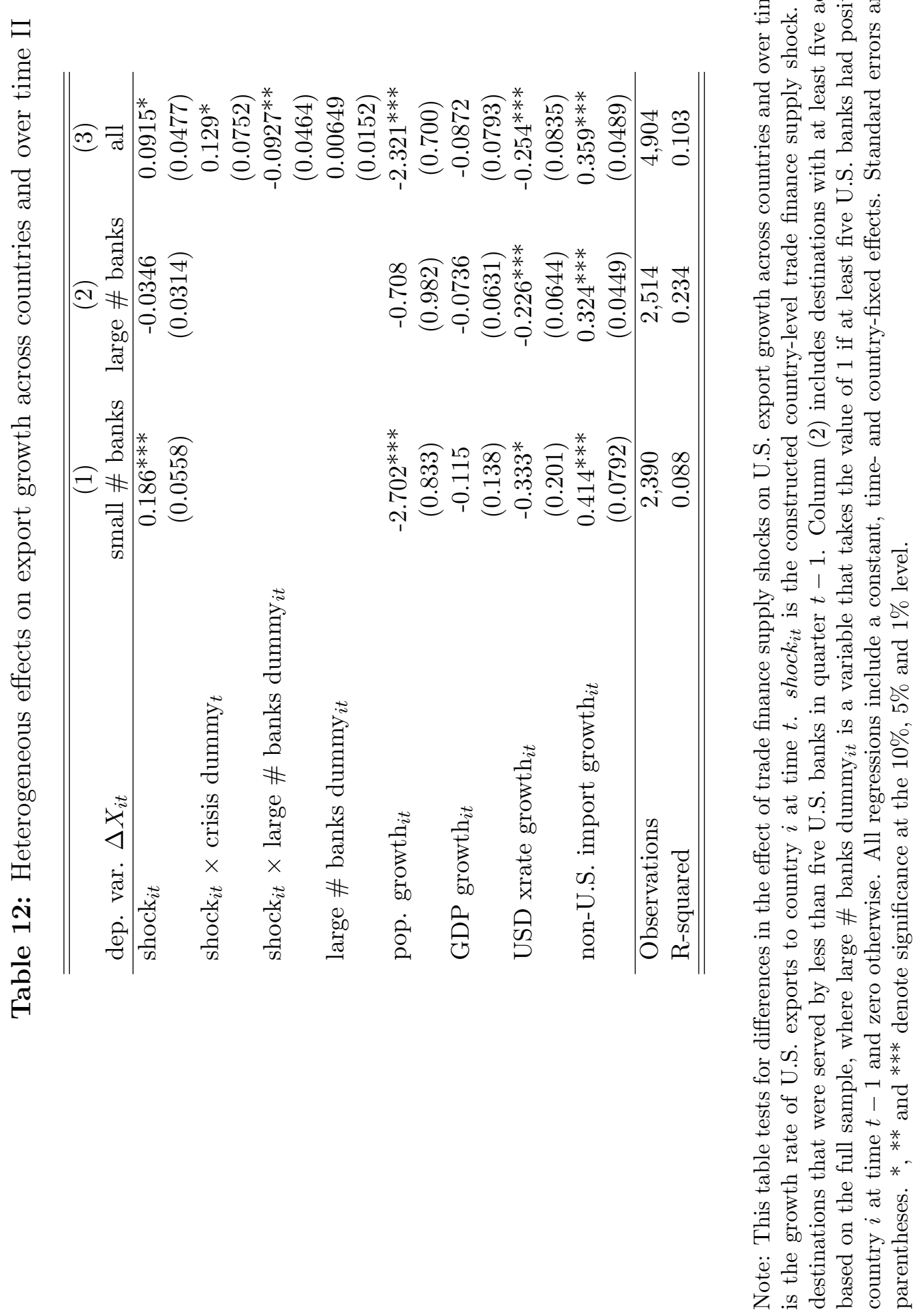




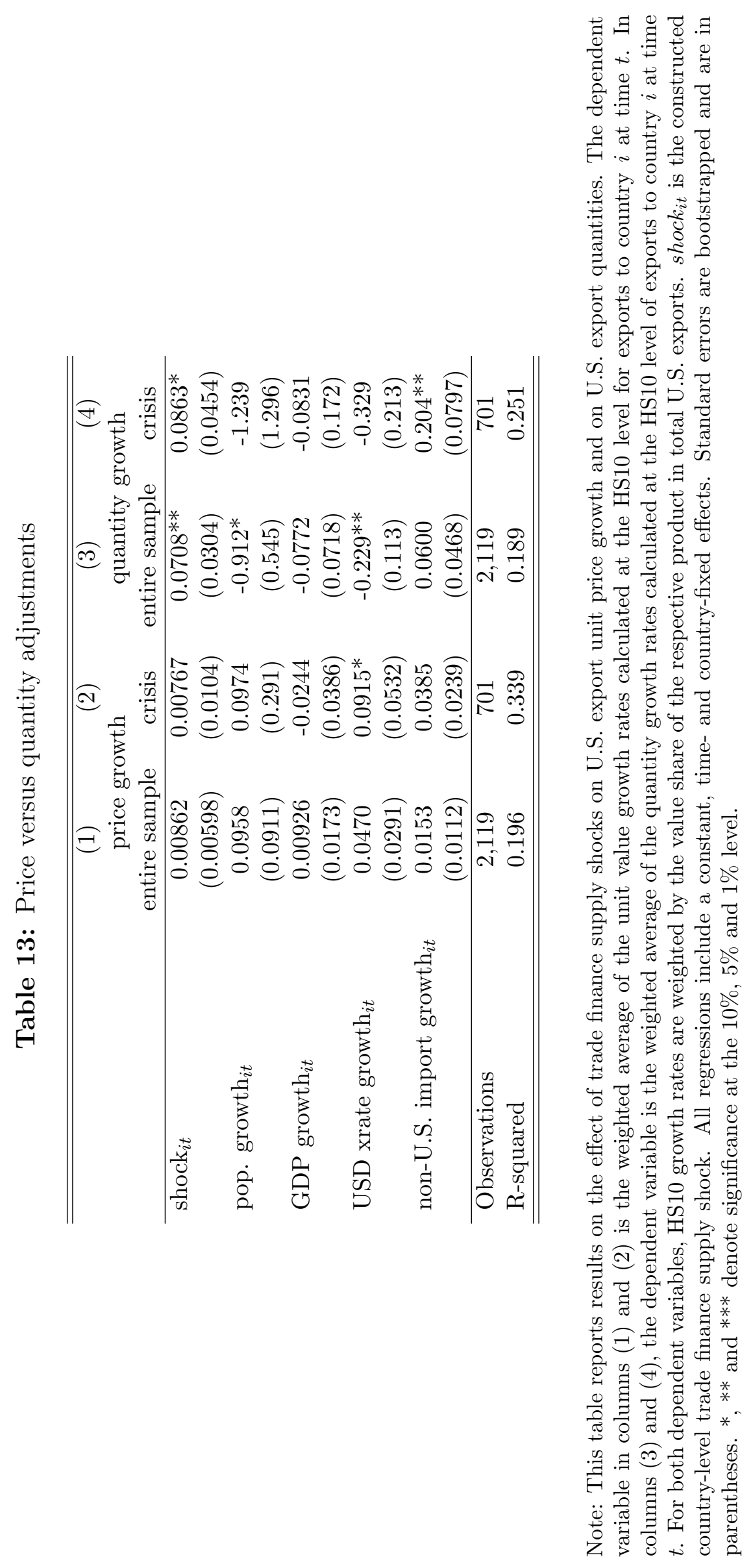




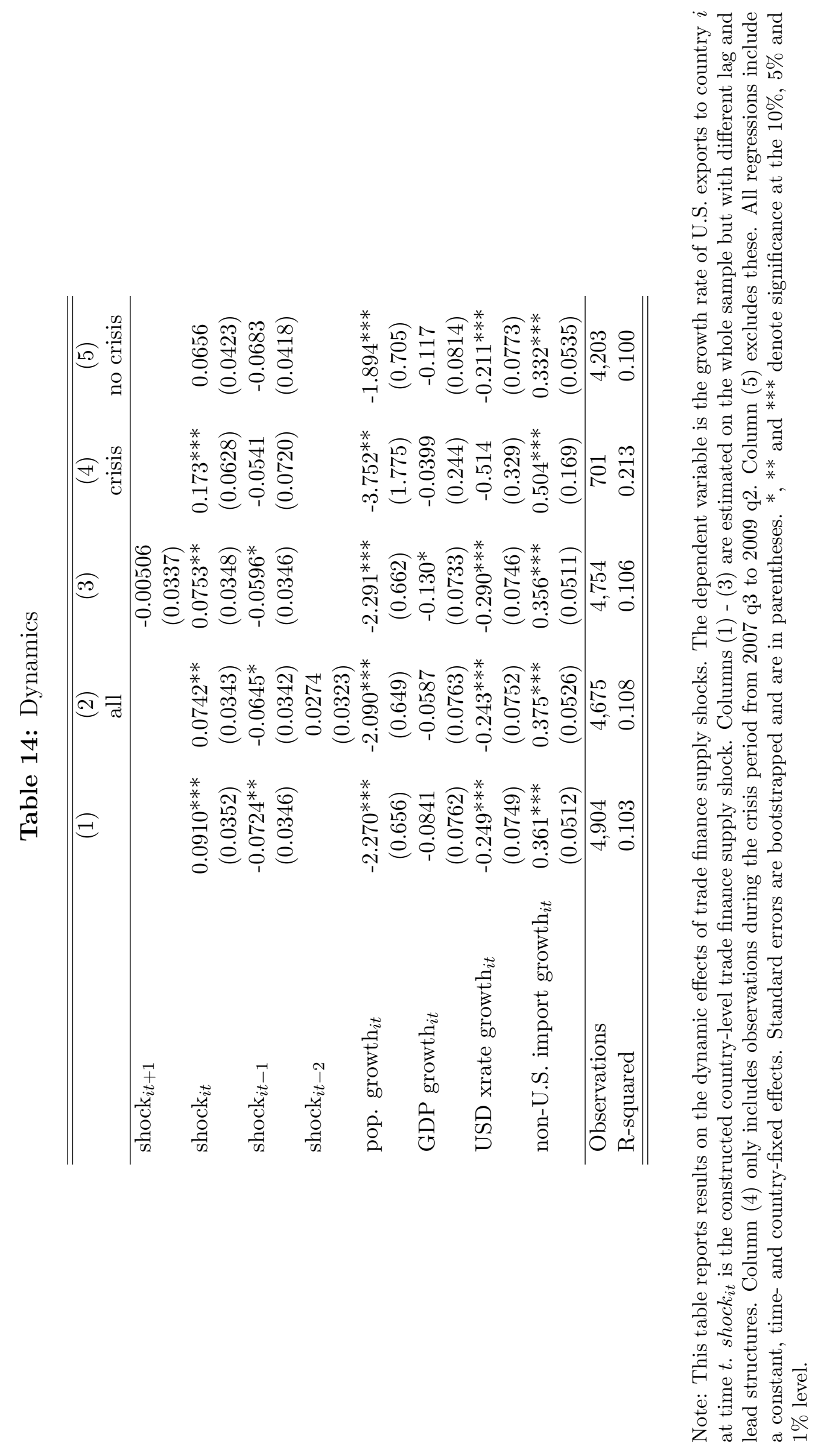




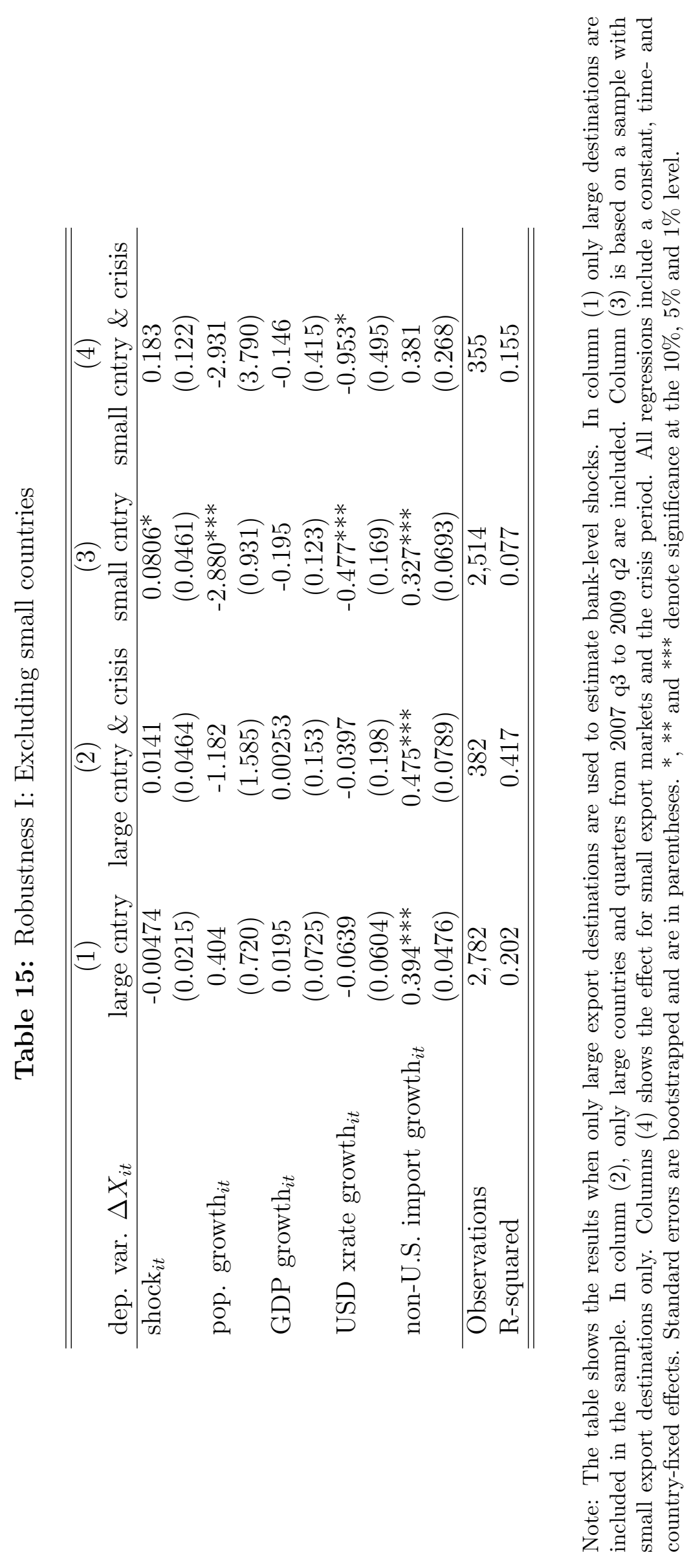


Table 16: Robustness II: Excluding countries with similar industry trade structure and regions

\begin{tabular}{|c|c|c|c|c|c|c|}
\hline & (1) & (2) & (3) & (4) & (5) & (6) \\
\hline dep. var. $\Delta X_{i t}$ & all & crisis & no crisis & all & crisis & no crisis \\
\hline \multirow[t]{2}{*}{$\operatorname{shock}_{i t}$} & $0.0677^{* *}$ & $0.126^{* *}$ & 0.0515 & $0.0529^{* *}$ & $0.116^{* *}$ & 0.0330 \\
\hline & $(0.0307)$ & $(0.0544)$ & $(0.0341)$ & $(0.0263)$ & $(0.0578)$ & $(0.0288)$ \\
\hline \multirow[t]{2}{*}{ pop. growth $_{i t}$} & $-2.285^{* * *}$ & -3.724 & $-1.909^{* *}$ & $-1.487^{* *}$ & -3.808 & $-1.849^{* *}$ \\
\hline & $(0.683)$ & $(2.653)$ & $(0.775)$ & $(0.596)$ & $(2.536)$ & $(0.791)$ \\
\hline \multirow[t]{2}{*}{ 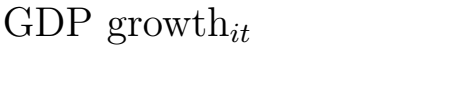 } & -0.0852 & -0.0577 & -0.115 & -0.0357 & -0.0709 & -0.107 \\
\hline & $(0.0717)$ & $(0.253)$ & $(0.08$ & $(0.0730)$ & $(0.274)$ & $(0.0827)$ \\
\hline \multirow{2}{*}{ USD xrate growth $_{i t}$} & $-0.250 * * *$ & $-0.534^{*}$ & $-0.210^{* *}$ & $-0.197 * * *$ & -0.542 & $-0.209^{* *}$ \\
\hline & $(0.0731)$ & $(0.279)$ & $(0.0849)$ & $(0.0698)$ & $(0.330)$ & $(0.0836)$ \\
\hline \multirow[t]{2}{*}{ non-U.S. import growth } & $0.362^{* * *}$ & $0.506^{* * *}$ & $0.332^{* * *}$ & $0.370^{* * *}$ & $0.503^{* *}$ & $0.332^{* * *}$ \\
\hline & $(0.0532)$ & $(0.171)$ & $(0.0534)$ & $(0.0524)$ & $(0.199)$ & $(0.0532)$ \\
\hline Observatio & 4,903 & 701 & 4,202 & 4,902 & 701 & 4,201 \\
\hline R-squared & 0.102 & 0.209 & 0.099 & 0.068 & 0.208 & 0.099 \\
\hline
\end{tabular}

Note: This table reports results of two robustness checks. The first exploits information on the similarity across destinations in terms of the goods they import from the U.S. The bank-level shocks that are used to compute the country-level shocks shock $k_{i t}$ for each country $i$ are obtained by excluding those 30 countries that are closest to country $i$ in terms of the industry structure of their U.S. imports (see. columns (1) to (3)). Columns (4) to (6) of the table report results of the second robustness check: the bank-level shocks that are used to compute the country-level shocks that apply to country $i$ are estimated without information from any country in country $i$ 's the region. All regressions include a constant, time- and country-fixed effects. Standard errors are bootstrapped and are in parentheses. ${ }^{*},{ }^{*}$ and ${ }^{* * *}$ denote significance at the $10 \%, 5 \%$ and $1 \%$ level. 


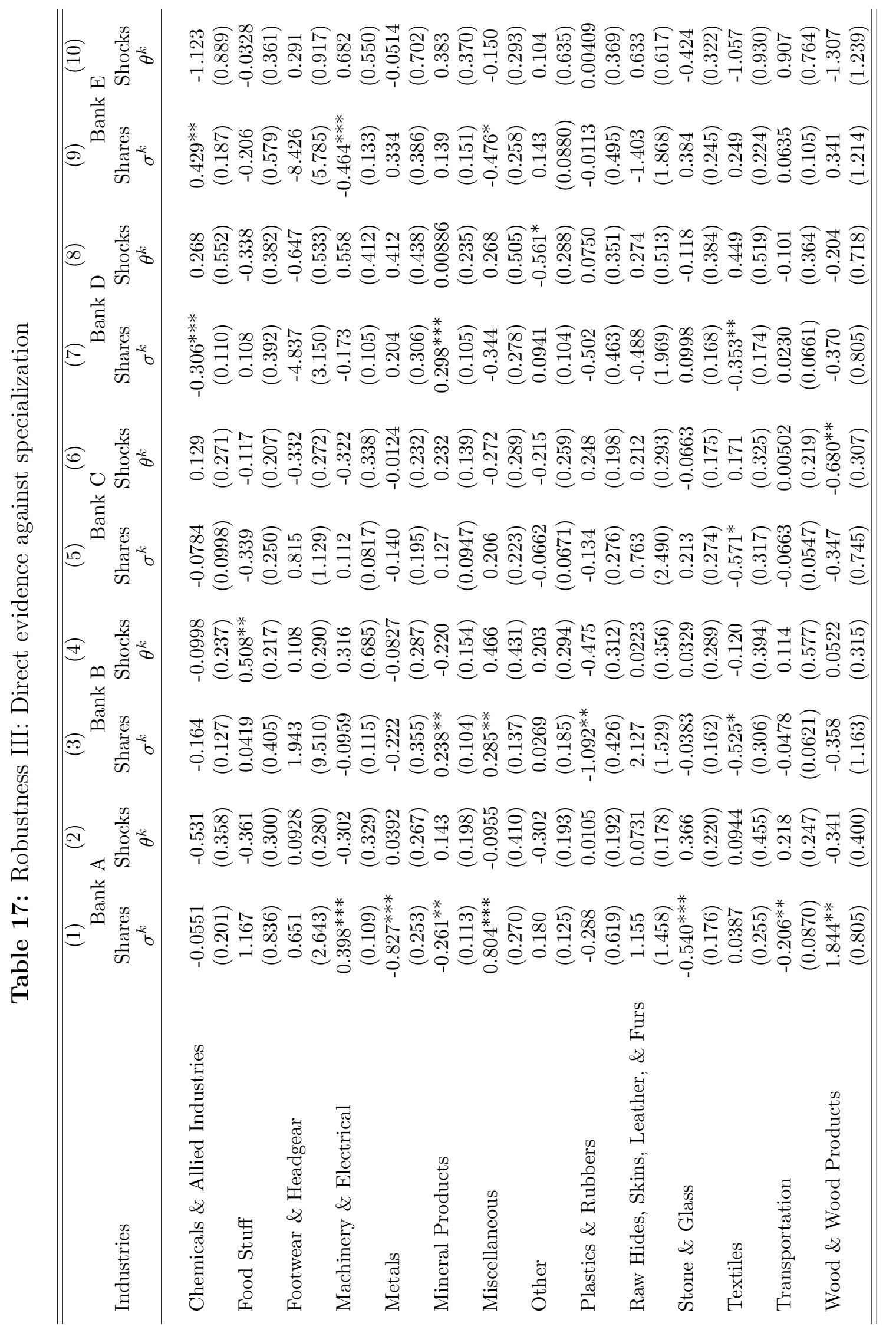

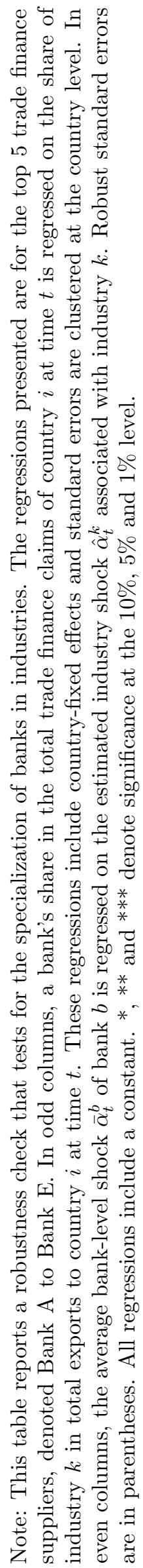


Table 18: Robustness IV: Alternative specification of banks' market shares

\begin{tabular}{|c|c|c|c|c|c|}
\hline & (1) & $(2)$ & $(3)$ & (4) & $(5)$ \\
\hline dep. var. $\Delta X_{i t}$ & 1q lag & $3 q$ lag & $4 q$ lag & $4 \mathrm{q}$ rolling av. & last year's av \\
\hline \multirow[t]{2}{*}{$\operatorname{shock}_{i t}$} & $0.0785^{* *}$ & $0.0655^{* *}$ & $0.0709^{*}$ & $0.0708^{*}$ & $0.0739 * *$ \\
\hline & $(0.0317)$ & $(0.0321)$ & $(0.0406)$ & $(0.0363)$ & $(0.0335)$ \\
\hline \multirow[t]{2}{*}{ pop. growth $_{i t}$} & $-2.288 * * *$ & $-2.295^{* * *}$ & $-2.282^{* * *}$ & $-2.267 * * *$ & $-2.289 * * *$ \\
\hline & $(0.694)$ & $(0.686)$ & $(0.639)$ & $(0.720)$ & $(0.728)$ \\
\hline \multirow[t]{2}{*}{ non-U.S. import growth $i t$} & $0.360 * * *$ & $0.360 * * *$ & $0.360 * * *$ & $0.361^{* * *}$ & $0.360 * * *$ \\
\hline & $(0.0532)$ & $(0.0488)$ & $(0.0479)$ & $(0.0553)$ & $(0.0534)$ \\
\hline \multirow[t]{2}{*}{ 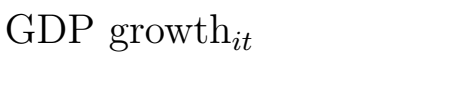 } & -0.0862 & -0.0845 & -0.0862 & -0.0868 & -0.0861 \\
\hline & $(0.0785)$ & $(0.0724)$ & $(0.0762)$ & $(0.0715)$ & $(0.0805)$ \\
\hline \multirow[t]{2}{*}{ USD xrate growth $\mathrm{th}_{i t}$} & $-0.254^{* * *}$ & $-0.251^{* * *}$ & $-0.251^{* * *}$ & $-0.250 * * *$ & $-0.254^{* * *}$ \\
\hline & $(0.0811)$ & $(0.0715)$ & $(0.0725)$ & $(0.0802)$ & $(0.0755)$ \\
\hline Observations & 4,904 & 4,904 & 4,904 & 4,904 & 4,904 \\
\hline R-squared & 0.102 & 0.101 & 0.101 & 0.101 & 0.102 \\
\hline
\end{tabular}

Note: This table shows that results are robust to the way country-level shocks are constructed. In each column, the variable $\operatorname{shock}_{i t}$ is constructed using different market shares $\phi_{i b t}$. The dependent variable is the growth rate of U.S. exports to country $i$ at time $t$. shock $k_{i t}$ is the constructed country-level trade finance supply shock. In column (1), the country-level shocks are constructed using one quarter lagged bank market shares. In column (2), three quarters lagged bank market shares are used. In column (3), bank market shares are lagged by four quarters. In column (4), market shares are averaged over the last four quarters. In column (5), a banks' average market share in the last year is computed and this market share is applied to construct all shocks in the next year. All regressions include a constant, time and country fixed effects. Standard errors are bootstrapped and are in parentheses. *, ** and *** denote significance at the 10\%, $5 \%$ and $1 \%$ level. 
Table 19: Robustness V: Placebo regressions and other checks

\begin{tabular}{lccc}
\hline \hline & $(1)$ & $(2)$ & $(3)$ \\
dep. var. $\Delta X_{i t}$ & EU15 export growth & cntry time trend & including zeros \\
\hline shock $_{i t}$ & 0.00189 & $0.0858^{* *}$ & $0.0862^{*}$ \\
& $(0.0290)$ & $(0.0372)$ & $(0.0487)$ \\
pop. growth & & $-2.325^{* * *}$ & -0.858 \\
& -0.502 & $(0.610)$ & $(2.124)$ \\
non-U.S. import growth & $(0.575)$ & $0.359^{* * *}$ & $0.142^{* * *}$ \\
& & $(0.0424)$ & $(0.0455)$ \\
GDP growth & & -0.0963 & 0.00229 \\
& $-0.101^{* *}$ & $(0.0864)$ & $(0.118)$ \\
USD xrate growth & $(0.0402)$ & $-0.255^{* *}$ & -0.245 \\
& $-0.356^{* * *}$ & $(0.103)$ & $(0.169)$ \\
\hline Observations & $(0.0486)$ & 4,904 & 782 \\
R-squared & 4,916 & 0.114 & 0.169 \\
\hline \hline
\end{tabular}

Note: This table shows the results of different robustness checks. In column (1), the dependent variable is growth in exports by EU15 countries to destination $i$. The regression in column (2) allows for country-specific time trends. In column (3), the bank-level shocks that are used to compute the variable $s_{h o c k}$ are obtained from estimating a modified version of equation 1, namely: $2 \frac{t f_{b c d}-t f_{b c t-1}}{t f_{b c d}+t f_{b c t-1}}=\alpha_{b t}+\beta_{c t}+\epsilon_{b c t}$. Regression are based on observations during the crisis period and the dependent variable is export growth to country $c$ at time $t$ computed as $2 \frac{e x p_{c t}-e x p_{c t-1}}{\exp p_{c t}+e x p_{c t-1}}$. All regressions include a constant, time and country fixed effects. Standard errors are bootstrapped and are in parentheses. ${ }^{*},{ }^{* *}$ and ${ }^{* * *}$ denote significance at the $10 \%, 5 \%$ and $1 \%$ level.

Table 20: Quantifications

\begin{tabular}{lccc}
\hline \hline & $\begin{array}{c}\text { Shock to Bank A } \\
\text { all times }\end{array}$ & $\begin{array}{c}\text { Shock to Bank B } \\
\text { all times }\end{array}$ & $\begin{array}{c}\text { Shock to all banks } \\
\text { crisis times }\end{array}$ \\
Region & $(1)$ & $(2)$ & $(3)$ \\
\hline East Asia and Pacific & $-0.469 \%$ & $-1.257 \%$ & $-3.64 \%$ \\
Europe and Central Asia & $-0.536 \%$ & $-1.382 \%$ & $-3.89 \%$ \\
South Asia & $-0.411 \%$ & $-1.861 \%$ & $-3.74 \%$ \\
Sub-Saharan Africa & $-2.86 \%$ & $-0.375 \%$ & $-3.97 \%$ \\
\hline \hline
\end{tabular}

Note: Columns (1) and (2) of the table show the effect on export growth in different world regions if two different large banks in the U.S. were to reduce its supply of trade finance by a value of -0.426 , which corresponds to the 10th percentile of the bank-level shock distribution. To calculate these numbers, the shock coefficient in column (3) of table 10 is used. Column (3) displays the effect on export growth if all U.S. banks were subject to a moderate shock of -0.245 , which corresponds to the 25 th percentile of the bank-level shock distribution during a crisis episode. The column is based on the coefficients displayed in column (8) of table 11, that is, the effect of a reduction in the supply of trade finance is allowed to differ across destinations with different sizes. 